IZA DP No. 5939

Conflict and its Impact on Educational Accumulation and Enrollment in Colombia:

What We Can Learn from Recent IDPs

Kate Wharton

Ruth Uwaifo Oyelere

August 2011 


\title{
Conflict and its Impact on Educational Accumulation and Enrollment in Colombia: What We Can Learn from Recent IDPs
}

\author{
Kate Wharton \\ Georgia Institute of Technology \\ Ruth Uwaifo Oyelere \\ Georgia Institute of Technology \\ and IZA
}

Discussion Paper No. 5939

August 2011

IZA

P.O. Box 7240

53072 Bonn

Germany

Phone: +49-228-3894-0

Fax: +49-228-3894-180

E-mail: iza@iza.org

Any opinions expressed here are those of the author(s) and not those of IZA. Research published in this series may include views on policy, but the institute itself takes no institutional policy positions.

The Institute for the Study of Labor (IZA) in Bonn is a local and virtual international research center and a place of communication between science, politics and business. IZA is an independent nonprofit organization supported by Deutsche Post Foundation. The center is associated with the University of Bonn and offers a stimulating research environment through its international network, workshops and conferences, data service, project support, research visits and doctoral program. IZA engages in (i) original and internationally competitive research in all fields of labor economics, (ii) development of policy concepts, and (iii) dissemination of research results and concepts to the interested public.

IZA Discussion Papers often represent preliminary work and are circulated to encourage discussion. Citation of such a paper should account for its provisional character. A revised version may be available directly from the author. 


\begin{abstract}

\section{Conflict and its Impact on Educational Accumulation and Enrollment in Colombia: What We Can Learn from Recent IDPs *}

Forty years of low-intensity internal armed conflict has made Colombia home to the world's second largest population of Internally Displaced Persons (IDPs). The effect of being directly impacted by conflict on a child's educational accumulation and enrollment is of particular concern because of the critical role that education plays in increasing human capital and productivity. This paper explores the educational accumulation and enrollment gap created by being directly affected by conflict. First, we show that children living in municipality with high conflict have a gap in education enrollment and accumulation. However, this gap is much smaller than the attainment and enrollment gap for those directly affected by the conflict (IDPs). We estimate the education accumulation and enrollment gaps for IDPs in comparison to non-migrants and other migrants respectively. Our results suggest significant education accumulation and enrollment gaps for children of IDPs that widens to over half a year in secondary school. The disparity in effects when we focus on direct exposure to conflict versus living in a municipality with conflict suggests a need to be careful when using the latter to estimate the impact of conflict.
\end{abstract}

JEL Classification: $\quad$ 124, O12, O15, J10

Keywords: educational attainment, school enrollment, Colombia, internal displacement, conflict

Corresponding author:

Ruth Uwaifo Oyelere

School of Economics

Georgia Institute of Technology

221 Bobby Dodd Way

Atlanta, GA 30332

USA

E-mail: ruth.uwaifo@econ.gatech.edu 


\section{Introduction}

For over forty years, Colombia has been troubled by armed conflict. The primary aggressor, the Revolutionary Armed Forces of Colombia (FARC) emerged as a revolutionary anti-imperialist Marxist organization in the 1960s in response to political exclusion of the rural poor. Later, right-wing paramilitaries formed as self-defense committees against the leftist FARC. Both irregular armed groups - guerrillas and paramilitaries - have since morphed into something dangerous, becoming closely tied to the narcotrafficking industry and other illegal activities for income. Although peace talks have occurred under nearly every president, attempts at negotiation and disarmament have failed to bring lasting peace.

One result of this disruptive, long-term conflict is the mass displacement of Colombians. Currently, Colombia ranks second in the world behind Sudan in the number of internally displaced persons (IDPs), with 3.3 million registered since 1997 according to the UNHCR 2009 Global Trends report. There is evidence that individuals who identify themselves as IDPS were forced to move as a direct result of fighting, land confiscation, massacre, fear of forced recruitment into the armed groups, and death threats. In addition, IDPs face significant obstacles to social and economic integration in receptor locations due to reduced social capital, family fragmentation, loss of assets, and difficulty acquiring a job. Kirchhoff and Ibáñez (2002) study changes of welfare for the displaced population and find that landowners suffered the greatest property losses, with 83 percent forced to abandon their land without compensation.

Although efforts have been made to protect IDPs and to assist them in resettlement, there is anecdotal evidence that IDPs are still vulnerable many years after migration. ${ }^{1}$ One possible explanation for this is that government aid to IDPs is restricted to the first three months of displacement. Meanwhile, longer-term income generation programs have had only limited success in helping IDP families return to their previous economic status. Ibáñez and Moya (2009) provide evidence of the problem with the USAID income-generation programs. Furthermore, many government programs have focused on the option of return rather than on integration of IDPs into the urban environment.

Education significantly increases the chances of improving welfare and escaping poverty, and it contributes significantly to the long-term integration of the vulnerable population into the larger society. Given the role of education in socioeconomic development, our goal in this paper is to investigate the impact of having parents directly affected by conflict on the education outcomes of

\footnotetext{
${ }^{1}$ The 1997 Law 387 dictates government policy concerning assistance to IDPs and establishes the Network of Social Solidarity (RSS) as the coordinating entity for the Strategic Plan for the Management of Internal Forced Displacement. However, government programs reach only a small portion of the registered IDP population, and UN agencies and other humanitarian organizations play an important role in assisting the displaced.
} 
school aged children. To meet this goal we answer four related questions.

First, is there an education accumulation and enrollment gap for children of those who live in municipalities with high conflict in comparison to others? Second, is there an education accumulation and enrollment gap for children of those directly affected by conflict (recent IDPs)? Third does living in a municipality with high conflict create similar education accumulation and enrollment gaps as being directly affected by conflict (recent IDPs)? Finally, how do recent IDPs compare to other other migrants in education accumulation and enrollment?

We make use of the Colombia 2005 Census data and data from the Humanitarian Situation Risk Index (HSRI) in this paper. To answer questions pertaining to educational accumulation we make use of linear regression models and fixed effect models and for questions related to enrollment we estimate probit models and compute marginal effects. Specifically to answer the first question, we create a dummy variable setting as one those who live in high conflict region. We identify individuals who fall into this category as those living in municipalities with conflict greater than the mean. Controlling for factors that predict enrollment and accumulation respectively and separating children 6-11 years old from those 12-17 year old, we estimate the gap between individuals in municipalities with high conflict and others. We find a slight gap in accumulation of about 0.036 of a year and a gap in probability of enrollment of about $1 \%$. However if we cluster at the municipal level, most of these estimated impacts are insignificant.

To answer the second question we first divide the sample of children into subgroups. The subgroups consists of several types of migrants linked with the reason for migration and also a group for non-migrants. We focus on recent IDPs because there is no way of identifying in our data IDPs who migrated more than five years ago. ${ }^{2}$ Using both our education accumulation model and our education enrollment empirical models, and controlling for important factors that predict school related outcomes, we estimate the gap in accumulation and enrollment for IDPs in comparison to non-migrants. We find that children of IDPs who are between 6-11 years have about one-fifth of a year less of schooling in comparison to non-migrants and the children 11-17 years old have a gap of about half-a year. With respect to enrollment, we find that children of IDPs ages 6-11 and 12-17 are $1.6 \%$ and $6.3 \%$ respectively less likely to be enrolled in school than non-migrants.

To answer the third question, we restrict our sample to only those in high conflict municipalities. Assuming IDPs found in these regions are not a select group and living in a conflict region creates similar effects as being directly affected by conflict, then there should be no accumulation or enrollment gap between children of IDPs and all other children living in a municipality of high conflict. We

\footnotetext{
${ }^{2}$ From now on we will refer to recent IDPs simply as IDPs. We also refer to those who are directly affected by conflict as IDPs.
} 
estimate our education accumulation and enrollment models on this sub-sample and find that a gap still exists and even grows. Specifically we find that for children of IDPs 6-11 and 12-17 years, the education accumulation gaps range from $0.21-0.23$ and $0.45-0.61$ less years of schooling depending on the level of conflict the sample is restricted to. With respect to enrollment, the evidence is mixed. For the 6-11 years cohort, there appears not to be an enrollment gap. In contrast, at the secondary level, children of IDPs in high conflict regions are significantly less likely than non-migrants to be enrolled in school (0.6-0.11). These estimated gaps in the high conflict municipalities though slightly larger are similar to the noted gaps when we considered all municipalities, especially the education accumulation gap.

The possible argument that non-migrants are not a good comparison group for IDPs leads to our last question. To address this question, we estimate both our accumulation and enrollment models limiting the sample to only migrants. ${ }^{3}$ We restrict our sample first to recent migrants given we can only detect recent IDPs in our data. However, as a robustness check, we also expand the sample to anyone who has migrated from their place of birth. We find that the accumulation and enrollment gap between children of IDPs and other migrants persists and is only slightly smaller than when IDPs are compared to non-migrants. For instance the accumulation gap for children ages 12-17 is half a year when IDPs are being compared to non-migrants but is about 0.4 of a year when compared to migrants. For children ages 6-11, there is less evidence of a gap when we restrict the sample to recent migrants. If we compare IDPs with all past migrants, the gap at this age level is significant but small. The slight drop in the gap also provides support for the potential selectivity of migrants.

We conduct some robustness checks on our main results using a fixed effect model and our inferences are still the same. The finding from our analysis suggest that all other things being equal, though living in a conflict region could affect a child's education accumulation and enrollment, the education impact is far less than being directly affected by conflict. In addition, we find that the education accumulation and enrollment impacts of having parents directly affected by conflict are more prominent at the secondary level.

This paper contributes to the literature by highlighting the direct impact of conflict on education accumulation and enrollment in Colombia. Although the past literature has looked at the impact of conflict on school related outcomes, it has focused on the impact of living in a municipality with high conflict versus being directly impacted by this conflict. Though the former is useful, looking

\footnotetext{
${ }^{3}$ It is important to mention that although we can argue that most other migrant groups are voluntary migrants and based on the past literature, such migrants are a select group who on average tend to fall behind in education accumulation and enrollment, it is hard argue that IDPs are voluntary migrants given their migration is linked with the occurrence of exogenous events.
} 
at individuals who have been directly impacted by conflict provides more insight on the impact of conflict on education outcomes. Also, to the best of our knowledge, we are the first to focus on estimating the educational accumulation and enrollment gaps for children whose parents were directly affected by conflict in Colombia.

The rest of our paper proceeds as follows. In section two we review the past literature on conflict and its education impacts and also highlight past literature on IDPs in Colombia. Section three is a summary of the data sets we used in this paper. In section four, we provide descriptive analysis of the data. Our empirical model is in section five, and section six provides a detailed summary of our finding and robustness checks. We conclude in section seven.

\section{Literature Review}

Education outcomes and the factors that affect these outcomes have been considered extensively in the literature. Specifically for Colombia, one factor that has been considered carefully is the opportunity to attend private school through a voucher program. Angrist et al (2002) examine the short term effects of the use of vouchers on students who had applied for the vouchers in Bogotá in 1995. The longer term effects of this program were also considered by Angrist et al (2006). They found that the voucher program increased secondary school completion rates by $15-20 \%$. Returns to education in Colombia have also been estimated by several authors ${ }^{4}$

Non-traditional factors that affect school attainment and enrollment have been analyzed both within and outside Colombia. Migration, income shocks, loss of life, and institutional quality are examples of such factors that have been examined in the past literature. ${ }^{5}$

Another non-traditional factor that affects attainment and enrollment highlighted in the more recent literature is conflict. However, the challenges of collecting accurate household level data during armed conflict has limited the growth of studies on this topic. In one of the few studies to assess the impact of conflict on education attainment using microeconomic data, Shemyakina (2011) studies the impact of the 1992-1998 civil conflict in Tajikistan on school enrollment and attainment. Shemyakina finds that exposure to the Tajik civil conflict had little or no effect on boys' enrollment. However, it had a large negative effect on girls' school enrollment. Similarly, Akresh and de Walque

\footnotetext{
${ }^{4}$ See Poveda and Sossa (2006), Gaston and Tenjo (1992), Psacharopoulos and Velez (1992, 1993) and Psacharopoulos (1994).

${ }^{5}$ See McKenzie and Rapoport (2010) for the impact of economic migration on education attainment in rural Mexico, Evans and Miguel (2007) for the effect of losing a parent and the importance of institutions, and Glewwe and Jacoby (1994) for the impact of availability and quality of school facilities on education attainment in Ghana. Also see Jacoby and Skoufias (1997), Duryea et al (2001), and Thomas et al (2004) for the impact of income shocks on schooling decisions in peaceful environments.
} 
(2008) study the effects of the 1994 Rwandan genocide on schooling. The authors find that children exposed to the Rwandan conflict lost nearly a half year of schooling compared to their peers who were not exposed. They were also $15 \%$ less likely to complete grades three and four. For Guatemala, Chamarbagwala and Morán (2011) examine the impact of exposure to the 36-year civil war on education outcomes for the rural Mayan population. In this disadvantaged group, the authors find a strong negative impact of conflict on education accumulation. For the three periods of the civil war identified, rural Mayan males showed a 0.27, 0.71, and 1.09 year decline in education attainment, while females showed a $0.12,0.47$, and 1.17 year decline. With very low education attainment overall, this amounts to a $23 \%$ and $30 \%$ decline in years of schooling during the third period of the war for males and females, respectively.

Compared to the conflicts in Tajikistan, Rwanda, and Guatemala, the conflict in Colombia is much more protracted and involves a greater number of irregular actors. These actors employ strategies that directly target civilians for expulsion, recruitment, and assassination. The relationship between violence and education in Colombia has been investigated. Barrera and Ibáñez (2004) develop a theoretical framework to explore the three ways in which violence can affect education. First, violence directly reduces the utility of individuals. Second, it destroys physical capital, creating uncertainty, deterring investment, and reducing productivity. Third, it reduces returns to education because education is not viewed as a value-enhancing commodity. ${ }^{6}$ The authors also show a statistically significant gap in enrollment rates between municipalities above and below the median national homicide rate. They find that violence has a negative impact on school enrollment at all ages, and that this effect is particularly large for young adults. The paper shows the negative effects of living in a violent municipality on school enrollment. However, it does not provide evidence on the impact of armed conflict on education outcomes of those directly affected by violence-the IDPs. It also does not discriminate between generalized violence and violence occurring as a direct result of the armed conflict. Dueñas and Sanchez (2007) go a step further by looking at the impact of armed conflict directly. These authors look at the impact of violence on another school related outcome, drop-out rates. Focusing on households in the eastern part of Colombia, they show using a duration model that the presence of illegal armed groups increases dropout rates, with increased effects for the poorest households. Though this paper considers the impact of the presence of armed conflict in an area on an education outcome, it does not look directly at IDPs, who we know are directly affected by the armed conflict. The Rodriguez and Sanchez (2009) paper builds on Dueñas and Sanchez (2007) by considering the joint decision to drop out of school and enter the labor market. The authors suggest that violence does not seem to affect education investments or child labor

\footnotetext{
${ }^{6}$ These channels through which armed conflict affects schooling are confirmed by Shemyakina (2011).
} 
decisions for younger children, but it does impact children over age 12. Interestingly, the authors find that the effect of violence varies primarily with age rather than with gender or household wealth. Although looking at the impact of local violence on education outcomes is useful, it cannot reveal the full impact of conflict on those directly affected.

Though the past research has not focused on the school enrollment and accumulation gap in Colombia, the plight of the displaced in general has been considered. First, Kirchoff and Ibáñez (2002) study the probability of individual or household migration in Colombia and find that households that have been directly affected by violence-either assassination or death threats-have a high probability of migrating. Of the IDPs interviewed, 58.2 percent reported that a household member received a death threat, compared to only 9.1 percent of non-displaced from the high-conflict regions. The authors provide extensive descriptive data on the IDP population gained from interviews in three urban centers. Results indicate that "security considerations are not the only determinants of the displacement decision." Rather, displacement may be motivated by individual characteristics, such as risk aversion and direct targeting by guerrilla and paramilitary groups. Ibáñez and Moya $(2006,2009)$ look at the vulnerability of IDPs over time and find that because IDPs are unable to successfully integrate into the urban economy, wellbeing in fact decreases and households are forced to take drastic measures in order to smooth consumption. Lozano-Gracia et al (2010) find that while the majority of IDPs migrate to geographically proximate locations, individuals from municipalities in the top 10 percent of violence levels will move far from their municipality of origin in hopes of distancing themselves from the conflict.

We will focus this paper on looking at the human capital investment gap between IDPs and other migrants, as well as non-migrants.

\section{Data}

The data we use to answer our questions of interest come from two sources: the Colombia 2005 Census and the the Office for the Coordination of Humanitarian Assistance. We accessed the 2005 Census, via IPUMS-International, ${ }^{7}$ and the majority of the data for this study comes from this source. This data includes over two million observations, a 5 percent sample of the 2005 Colombian Census, which is notable for its accuracy and coverage.

We are able to identify IDPs from this data using those who identify themselves as migrants and state conflict as the reason for migration. This technique of identifying IDPs has two potential limitations. First, we are unable to identify IDPs who moved more than five years ago. This

\footnotetext{
${ }^{7}$ Minnesota Population Center. Integrated Public Use Microdata Series, International: Version 6.0 [Machinereadable database]. Minneapolis: University of Minnesota, 2010.
} 
is because though we can identify indirectly all who have migrated by comparing birth place to current place of residence, the question that allows us to identify IDPs is restricted to those who have migrated in the last five years. This limitation implies that we are unable to look at the long term effects of conflict on school attainment for the children of the displaced. Second, the responses to the question of why you migrated are mutually exclusive, so each person selects only one motivation for migration. This could potentially be an issue if an individual migrated for more than one reason. However, we are of the opinion that this restriction is good for our own identification because it forces people to pick the most important reason for migrating. This allows us isolate IDPs (our group of interest) who are more likely to select the directly affected by conflict option. However, about $0.32 \%$ of the sample of recent migrants do not report any reason for migration so there is a potential that this group could also include IDPs. We create a separate category for these observations but given the sample size of this group is small, we are not too worried about these observations potential impacts. ${ }^{8}$ The census data is appropriate for this analysis not only because it has a large sample and allows us identify IDPs, but also because it has a wide range of variables that we can make use of as controls in our enrollment and accumulation models. The major limitation of the data is the lack of information on income. However, the Colombian census has many indicators for poverty and wealth which we can use as proxies for income.

The source of data concerning humanitarian risk, conflict, capacity, social, and economic levels per municipality is the Humanitarian Situation Risk Index (HSRI), calculated by the Office for the Coordination of Humanitarian Assistance in collaboration with the Universidad Santo Tomas in 2008. The HSRI was developed with the purpose of calculating the probability that a humanitarian situation will occur at the municipality level in Colombia. Four sub-indices of risk are calculated and used to determine the overall humanitarian risk: conflict, response capacity, social, and economic. Information used to calculate the HSRI and sub-indices comes from the National Administrative Statistics Department (DANE), the Ministry of Social Protection, the National Planning Department, the Social Action and Unified Registry System, the National Education Ministry, the Central Judicial Police Directorate, the Center for Criminological Investigations, the Vice-presidency's Mines Observatory, Free Country (an NGO), the Center for Conflict Analysis Resources (a think-tank), and the World Bank. A HSRI value and a value for each of the risk indicators is provided for each of 1,100 Colombian municipalities. However, only 532 municipalities or groups of municipalities are defined in the 2005 Census because in many cases small municipalities are grouped together as

\footnotetext{
${ }^{8}$ We do not suggest that our method identifies the sample of those who register as IDPs during our data period. However, we are confident that we capture most of those whose move was driven by being directly affected by conflict from 2000-2005.
} 
one location in the census. In order to incorporate the HSRI and its sub-indices data into the 2005 Census data (which we will be using for our analyses), we input for each individual, the value of each index and also the composite index for their municipality. In some instances as mentioned above, the municipality defined in the census is an agglomeration of multiple small municipalities. Given the risk indices were defined for all municipalities in the risk data, we find the average HSRI and other sub-index values for municipalities grouped together in the census and assign these average values to all individuals who are defined in the census as belonging to that municipality grouping. Specifics of the variables included in each sub index can be found in Appendix 1.

\section{Descriptives}

In this section we present some descriptive statistics to further motivate our discussion on the educational attainment and enrollment of IDPs. ${ }^{9}$

Table 1 presents summary statistics of basic indicators for IDPs in comparison to other migrants. Notice that in comparison to other migrants, IDPs are older, more likely to be male, more likely to have more children in the family, less likely to be married, less likely to be in an urban area, less likely to own their dwelling, less likely to be literate, less likely to be employed, and more likely to be disabled. However, if we compare IDPs with non-migrants, we see less of a difference with respect to being married, gender, living in an urban area, employment, and race. Notice, however, that IDPs differ significantly in some variables which may be indicators of experiences characteristic of those who have been directly affected by conflict. For instance, IDPs are more likely than any other group to be disabled and they also have the lowest likelihood of owning a dwelling. With respect to education accumulation, we note from Table 1 that IDPs have lower mean educational attainment than other migrants and non-migrants. One glaring difference between this group and everyone else is that they have significantly more children than non-migrants or other migrants despite having similar probability of being married and similar mean age. This difference may suggest that families with children are more likely to be directly affected by conflict than those without or that families with children are more likely to migrate if directly affected by conflict. The summary in Table 1 confirms the existing literature that IDPs are vulnerable. Although the literature suggests that migrants are a select set with exceptional drive, the findings below suggests that IDPs do not fit the mould of other migrants.

To further motivate our discussion, we present some enrollment statistics. Table 2 shows proportion enrolled in school by age cohort and migration status. In Table 2, the displaced population

\footnotetext{
${ }^{9}$ It should be noted that through out this study, "IDPs" refers to Colombians who have migrated because of conflict, according to the 2005 Census. Natural disaster migrants are treated as a separate category.
} 
Table 1: 2005 Census: Descriptive Statistics

\begin{tabular}{lllll}
\hline \hline Category & IDPs & Other Migrants & Non-Migrants & All \\
\hline Age & 27.059 & 26.691 & 29.06 & 28.58559 \\
Sex (male) & 0.509 & 0.492 & 0.503 & 0.501 \\
No. children & 0.984 & 0.787 & 0.809 & 0.807 \\
Married & 0.37 & 0.401 & 0.354 & 0.3631 \\
Urban & 0.523 & 0.702 & 0.553 & 0.581 \\
Race: White & 0.705 & 0.836 & 0.796 & 0.803 \\
Race: Black & 0.17 & 0.11 & 0.103 & 0.105 \\
Race: indigenous & 0.072 & 0.03 & 0.071 & 0.063 \\
Yrs school & 4.354 & 6.321 & 5.125 & 5.349 \\
Literacy & 0.738 & 0.823 & 0.739 & 0.755 \\
Employed & 0.307 & 0.366 & 0.273 & 0.291 \\
Disabled & 0.082 & 0.058 & 0.729 & 0.07 \\
\hline \hline
\end{tabular}

is compared to other migrants and non-migrants. The results suggest that the displaced are less likely to be enrolled in school than any other group in all school age categories. The enrollment gap is particularly substantial for the 12-14 and 15-19 age cohorts, which correspond to secondary education.

Table 2: 2005 Census: Proportion Enrolled in School

\begin{tabular}{lcccc}
\hline \hline Age Cohort & IDPs & Other Migrants & Non-Migrants & All \\
\hline $6-11$ & 0.83 & 0.901 & 0.891 & 0.892 \\
$12-14$ & 0.744 & 0.836 & 0.831 & 0.831 \\
$15-16$ & 0.584 & 0.664 & 0.689 & 0.683 \\
$17-21$ & 0.253 & 0.322 & 0.331 & 0.328 \\
$22-25$ & 0.097 & 0.149 & 0.135 & 0.138 \\
\hline \hline
\end{tabular}

In Table 3, we compare IDPs with other vulnerable groups to highlight the fact that though our discussion is focused on IDPs, IDPs are not the only educationally vulnerable population. The other vulnerable groups we isolate are those who migrated because of natural disaster, the disabled, and the poor. ${ }^{10}$ At the level of primary education, ages 6-11, the displaced are more likely to be enrolled than any of these other groups of vulnerable migrants, with $81.1 \%$ enrollment. The displaced, the natural disaster migrants, and the disabled have very similar enrollment rates from ages 12-21. In

\footnotetext{
${ }^{10}$ We identify the poor in this Table through the wall materials of their housing.
} 
the 22-25 age cohort, which corresponds with graduate level university education, the displaced lag behind these other groups. Not surprising, at all ages, the very poor lag significantly behind in terms of educational enrollment which suggests the need to control for income and disability in our regression analysis.

Table 3: 2005 Census: Enrollment Statistics for Vulnerable Groups

\begin{tabular}{lllll}
\hline \hline Age Cohort & $\begin{array}{l}\text { Migrated: } \\
\text { Displaced }\end{array}$ & $\begin{array}{l}\text { Migrated: } \\
\text { Natural } \\
\text { Disaster }\end{array}$ & Disabled & $\begin{array}{l}\text { Poor } \\
\text { living } \\
\text { conditions }\end{array}$ \\
\hline $6-11$ & 0.83 & 0.814 & 0.702 & 0.779 \\
$12-14$ & 0.744 & 0.74 & 0.723 & 0.706 \\
$15-16$ & 0.584 & 0.559 & 0.58 & 0.511 \\
$17-21$ & 0.253 & 0.27 & 0.277 & 0.203 \\
$22-25$ & 0.097 & 0.114 & 0.114 & 0.065 \\
\hline \hline
\end{tabular}

Table 4 highlights the educational attainment of the displaced, other migrants, and non-migrants. Table 4 indicates that the displaced have significantly lower educational attainment than any of the other groups, and that the educational attainment gap grows over time. These results can also be seen graphically in Figure 1. The gap grows significantly in the 22-25 age cohort, with the displaced achieving approximately 2.3 fewer years of schooling than non-displaced migrants and 1.3 fewer years than non-migrants. This difference is likely attributable to the large proportion of other migrants who have moved for study and are therefore expected to reach very high educational attainment. It is also notable from Table 4 that educational attainment is on average lower in the 26-30 cohort than in both the 17-21 and 22-25 age cohort, suggesting an improvement over time in human capital accumulation in Colombia.

Table 4: 2005 Census: Educational Attainment

\begin{tabular}{lcccc}
\hline \hline Age Cohort & Displaced & Other Migrants & Non-Migrants & \\
\hline $6-11$ & 1.948 & 2.188 & 2.317 & 2.287 \\
$12-14$ & 4.728 & 5.633 & 5.58 & 5.578 \\
$15-16$ & 6.257 & 7.243 & 7.109 & 7.122 \\
$17-21$ & 6.812 & 8.554 & 7.926 & 8.045 \\
$22-25$ & 6.732 & 9.064 & 7.992 & 8.253 \\
$26-30$ & 6.176 & 8.877 & 7.396 & 7.777 \\
\hline \hline
\end{tabular}




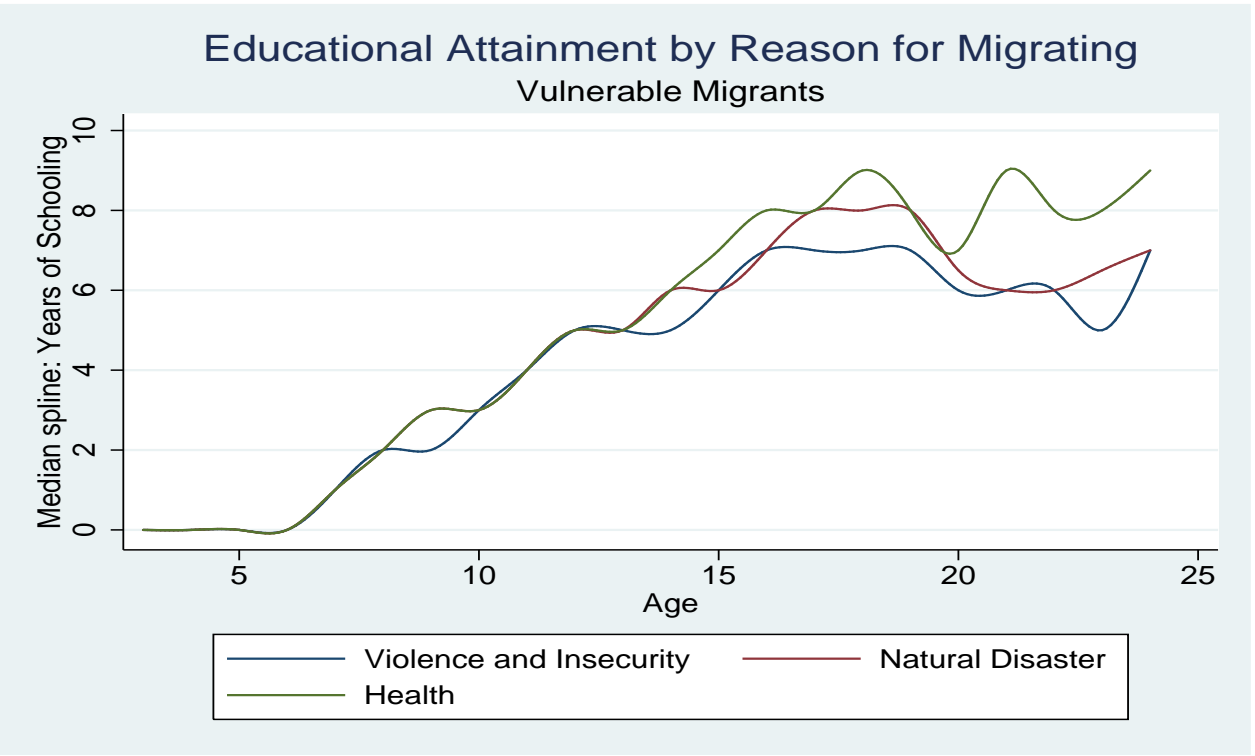

Figure 1:

Even if we focus solely on potentially vulnerable migrants (migrants who have moved because of natural disaster, health, or displacement) as in Figure 2, we still see IDPs end up with lower levels of attainment. Notice that IDPs migrants appear to achieve similar educational attainments as other vulnerable migrants until secondary school, when health migrants begin to move ahead and the displaced begin to fall behind. By age 18, the gap has widened significantly, with the displaced achieving approximately 3 years less schooling than those who migrated for health reasons, and natural disaster victims falling somewhere in between.

One of the points we make in this paper is that IDPs are not like other most other migrants, especially those who migrated for endogenous versus exogenous factors. Figure 3 highlights the school attainment trend for three group of regular migrants: those who migrated for work, family, and study. The results are logically consistent, with study migrants achieving highest years of schooling, and work migrants achieving the fewest. It should be noted that again, the gap does not emerge until secondary education. All of these non-vulnerable groups achieve higher educational attainment than the displaced population.

These preliminary descriptive statistics suggest IDPs have experienced something that makes them different. In this paper, we focus on the education accumulation and enrollment impact of direct exposure to conflict on children. Even though the above results suggest lower mean education accumulation and enrollment for IDPs or their children, this result does not imply that conflict is 


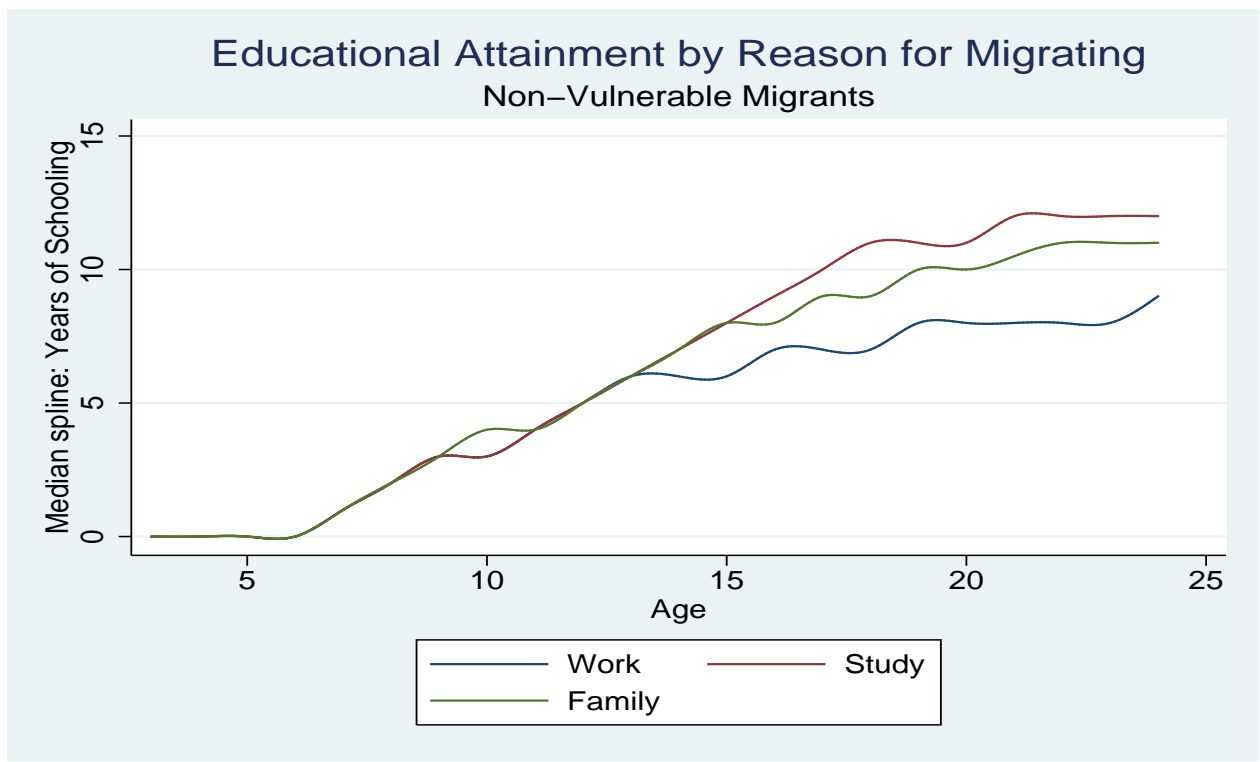

Figure 2:

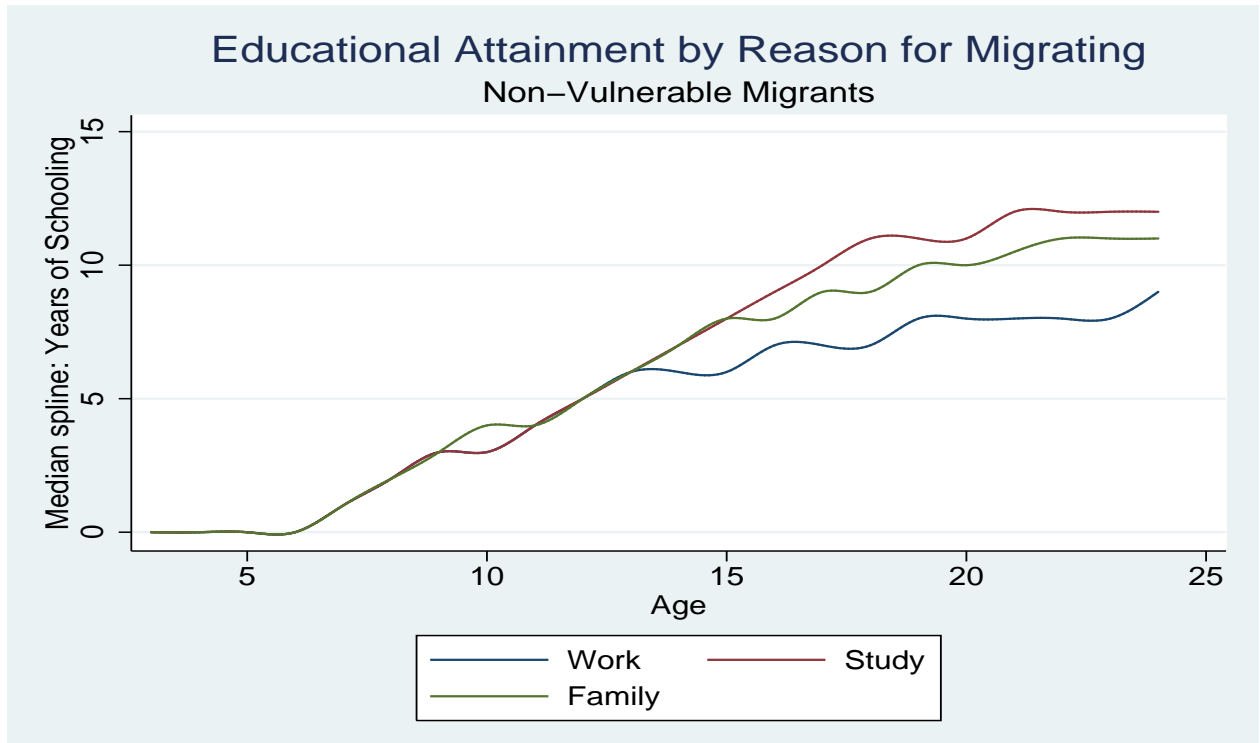

Figure 3: 
responsible for this gap. It is possible that children of IDPs have parents with lower education or parents who are poorer. In this scenario, a gap in educational attainment or enrollment ins expected. To evaluate the possible effect of direct exposure to conflict, we turn to econometric analysis.

\section{$5 \quad$ Empirical Strategy}

As mentioned above, we focus on four main questions in this paper. First, is there an education enrollment and accumulation gap for children of those who live in municipalities with high conflict in comparison to others? Second, is there an education accumulation and enrollment gap for children of those directly affected by conflict? Third, does living in a municipality with high conflict create similar education accumulation and enrollment gaps as being directly affected by conflict? Finally, how do IDPs compare to other migrants in education accumulation and enrollment?

To answer our first question, we estimate a school accumulation empirical model (equation (1)) and a school enrollment empirical model (equation (2)).

$$
Y_{c}=\alpha_{c}+\gamma_{c} X_{c}+\delta_{c} F_{c}+\beta_{c} R_{c}+\theta_{c} W_{c}+\epsilon_{c}
$$

Here $\mathrm{Y}$ is a vector of years of schooling for a particular age cohort c. We focus on two age cohorts in our analysis: ages 6-11 and ages 12-17. We choose to focus on these cohorts because we have information on important controls that affect our outcomes of interest for these two cohorts. Moreover, these age groups corresponds with Colombia's school system - primary and secondary age ranges. $\mathrm{X}$ is a matrix of variables that affects a child's schooling in cohort c. This matrix includes variables like gender, economic status correlates, family size, mother's years of schooling, father's years of schooling, number of children of mother, class of work of father, class of work of mother, and employment status of father. $\mathrm{F}$ is a matrix of dummy variables that are important to control for, such as state of residence and race. $\mathrm{R}$ is a dummy variable that takes a value of 1 if a child is in a municipality with high conflict and 0 if otherwise. The matrix $\mathrm{W}$ consists of region controls such as if an area is urban or rural or the social capacity of a municipality. epsilon is the error term. The inclusion of parent related variable reduces the potential of omitted variable bias given the importance of parents' education as a predictor of child's education. However, inclusion of this variable comes at a cost given not all children in the sample report information about parents. We drop all children who do not have information on both parents' education from the sample we estimate. However, we address later on in the paper the question of whether the use of the restricted sample for which information on parents is available creates a biased estimate of the coefficients we are interested in. 
To answer the second part of question 1, we assume that a child being enrolled in school is a function of a set of variables $\mathrm{Z}$. In this case, our independent variable is a binary variable that takes a 1 when a child in a particular age cohort is enrolled in schooling and 0 otherwise. We rewrite equation (2) assuming a probit modeling strategy. The $\Phi$ in equation (3) our empirical school enrollment model, indicates the standard normal distribution. The description of the variables is the same as in equation (1) above. Using a probit model, we estimate equation (3) and find the marginal effects. The marginal effects represent the impact of a unit change in each independent continuous variable on the probability of being enrolled in school. This provides a straight forward interpretation of estimated results from the probit models. For dummy variables like $\mathrm{R}$, which is the focus of the first question, the interpretation of marginal effects is slightly different. The marginal estimate captures the difference in the probability of being enrolled in school for a particular group dummy relative to the baseline group. In the case of $\mathrm{R}$, the estimated marginal effect captures the probability of being enrolled in school for a certain age cohort for those living in a high conflict municipality relative to those who do not.

$$
\begin{gathered}
\operatorname{Prob}(S=1)=F\left(\beta^{\prime} Z\right) \\
\operatorname{Prob}(S=1)=\Phi(\alpha+\zeta X+\xi F+\lambda R+\chi W+\mu)
\end{gathered}
$$

For the second question, our empirical strategy is to first estimate equation (4) using OLS. Notice equation (4) is very similar to equation (1). The difference lies in the matrix $M$ being include in equation (4) instead of dummy variable R. To answer the second part of question two, we also alter our enrollment empirical model, equation (3), dropping $\mathrm{R}$ and including $\mathrm{M}$ as in equation (5). Once again we compute and report marginal effects for the enrollment model.

$$
Y_{c}=\alpha_{c}+\gamma_{c} X_{c}+\delta_{c} F_{c}+\beta_{c} M_{c}+\theta_{c} W_{c}+\varepsilon_{c}
$$

$\mathrm{M}$ is a dummy variable matrix that divides the population based on cause for migration in the last five years. For these dummy variables the base group are people who have not moved in the last five years. We call this group non-migrants. Among the migrant cause dummies, we have a dummy for those who migrated because of violence or conflict. This is our identifier of IDPs, and the dummy we will focus on in answering the question of if there is an education and accumulation gap for IDPs.

$$
\operatorname{Prob}(S=1)=\Phi(\alpha+\zeta X+\xi F+\lambda M+\chi W+v)
$$


To address the third question, we re-estimate equations (4) and (5) on the sample of those affected solely by conflict. To test the sensitivity of our result, we try different ways of defining the population affected by conflict. First, we consider states with a conflict index above the mean. Next we consider municipalities with conflict index above the mean. Lastly, we consider municipalities with very high conflict (in the top quartile of the conflict index).

We address our last question by once again slightly altering equations (1) and (3). In contrast to the first two questions for which we focus on both migrants and non-migrants, here we restrict our sample to only migrants. In addition, we alter the dummy variable $\mathrm{R}$. Recall for the first question, $\mathrm{R}=1$ if a person lives in a municipality with high conflict. However for this question, $\mathrm{R}$ takes the value of 1 if a person is an IDP (migrant directly affected by conflict) and 0 if the person is a migrant for any other reason.

\subsection{Potential Econometric Issues with estimating the impact of conflict}

Given our focus on estimating the school accumulation and school enrollment gap linked with conflict, it is important to highlight some basic issues that could make deriving consistent estimates of these gaps difficult. First, IDPs are migrants, and in general analysis focused on migrants could be plagued with issues of selectivity. Migrants are a select group of people, and in general, looking at migrants' outcomes or the impact of migrations on certain outcomes without controlling for selection could lead to biased estimates. However, IDPs are a unique group of migrants in that their migration is motivated by being directly affected by conflict. We can think of IDPs as involuntary migrants linked to exogenous forces. In contrast, migrants who moved for study, family reasons or work can be viewed as voluntary migrants linked to endogenous factors. Kirchhoff and Ibáñez (2002) note that not everyone in regions of high conflict migrate. Those who do leave have usually been directly affected in a significant way by the conflict, having lost family or property or received threats of such. Table 1 of Kirchhoff and Ibáñez (2002), highlights that $58.2 \%$ of IDPs surveyed received a death threat before migrating. In contrast, only $9.1 \%$ of those who did not migrate living in the same high conflict region as were the IDPs migrated from, received similar threat. Given the uniqueness of the IDPs' experience and the exogenous nature of being directly affected by conflict, it may be possible to look at IDPs as a different kind of migrants that may not suffer from the selection bias plaguing other migrants. Assuming this is true, then in a regression in which we control for the factors that typically predict school attainment, the estimate of the gap in school attainment or enrollment between the IDP's and non-migrants can give us an approximate estimate of the impact of being directly affected by conflict. If however, non-migrants on average look very different from 
IDPs, then the estimated education accumulation or enrollment gap could be upward biased. ${ }^{11}$

Another variable that several authors have noted to be endogenous in the accumulation and enrollment models is conflict. Conflict could be correlated with individuals being poor or living in an area with low levels of social capacity. Because both of these factors are important for human capital investment and school enrollment, an analysis focused on conflict could over estimate the impact of conflict if we do not control for capacity or address the potential endogeneity in the conflict variable. Although the level of conflict in a region is merely a control rather than our major variable of interest for our second and third question, conflict in a region is used to define the exposure to conflict dummy for our first question and is also relevant for our last question. We try to avoid the potential bias in estimating the impact of exposure to conflict by controlling for the capacity in a municipality and also by including several poverty correlates and wealth indicators. ${ }^{12}$ It is also important to mention that Rodriguez and Sanchez (2009) highlight another potential channel of omitted variable bias in estimating the impact of conflict on dropout rate. ${ }^{13}$ They suggest that although exposure to conflict affects school enrollment, pressure to drop out of school also affects dropout rates and is correlated with conflict. Therefore, it is possible to attribute to conflict the impact of this pressure on drop out rates or enrollment. Although we think this kind of bias will be marginal, one way to deal with this potential bias is to use instrumental variables. We do not explore this route because we are unable find a suitable instrument that satisfies exclusion restriction and including a weak instrument could create more bias in our estimated coefficients than if an OLS estimate was derived. ${ }^{14}$ Although Rodriguez and Sanchez (2009) use lagged homicide capture rates as an instrument, we are not of the opinion that this variable satisfies exclusion restrictions. One possible way to deal with this omitted variable which we explore in our paper is to restrict the sample to high conflict communities. In these communities, it is safe to assume that the pressure to drop out should on average be the same. Hence, the estimated enrollment and attainment gaps for IDPs in comparison to non-migrants living in these high conflict region will not be upward biased because the missing variable has the same distribution across both groups.

We also explore a fixed effect technique to overcome this problem. Pressure to migrate and

\footnotetext{
${ }^{11}$ We are of the opinion that we can make this assumption because we compared summary statistics for variables like age, family size, marital status and gender for IDPs, migrants and non-migrants. We noted only slight differences between IDPs and non-migrants but bigger differences between non-migrants and migrants. We do not compare summary statistics for variables related to education, employment or location (urban vs rural) as we expect that these variables will be affected by being exposed to conflict and so should differ across IDPs and non-migrants.

${ }^{12}$ More on the capacity index and what is used in its computation is in the appendix. See Table 17 in the appendix. In the data section of the paper we describe how we impute the data on conflict and capacity into our census data for 2005. The conflict and capacity data are measured over different periods.

${ }^{13}$ Enrollment, our focus in this paper, is inversely related to dropout rate.

${ }^{14}$ See Staiger and Stock 1997 for more on weak instruments.
} 


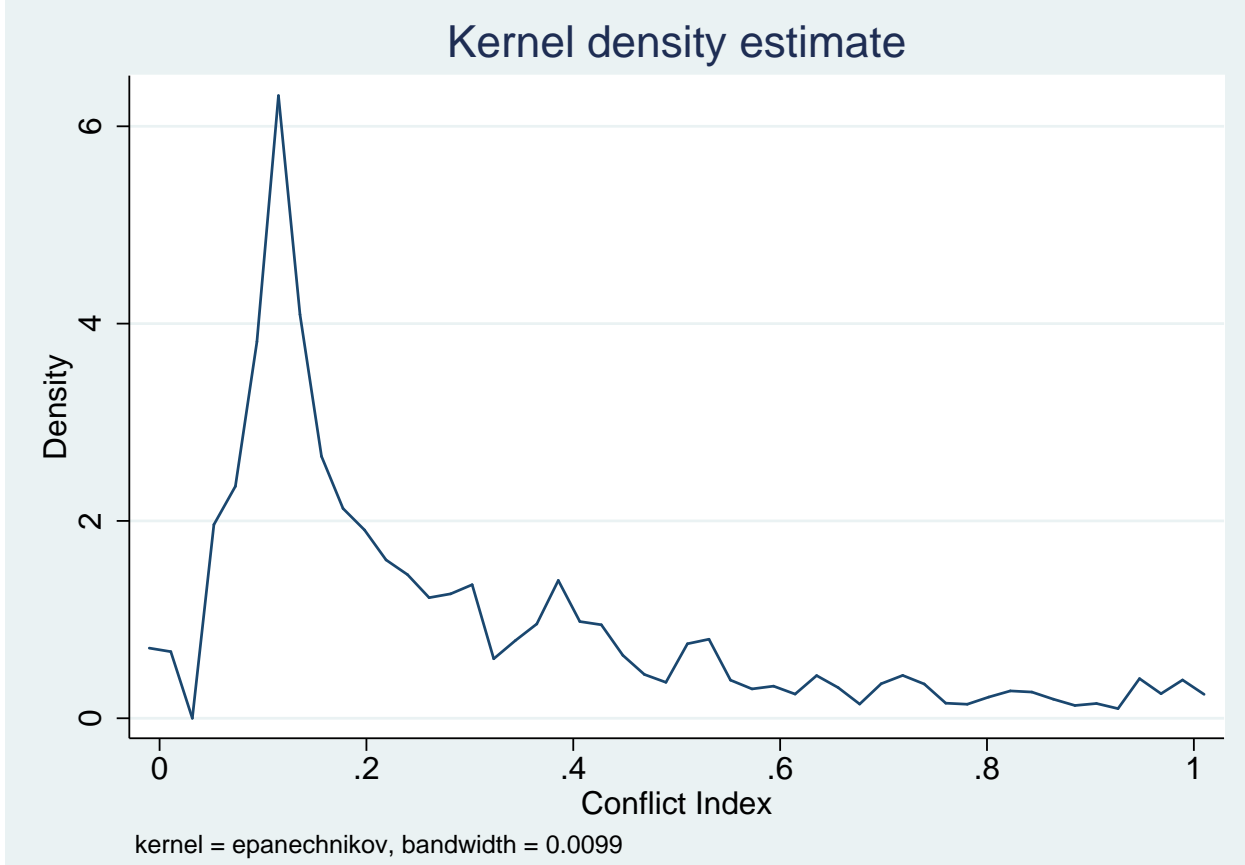

Figure 4: Kernel Density for Conflict Index

level of conflict are similar within a municipality. In fact, conflict measures are all calculated at the municipality level. Moreover, social and economic infrastructure and other related variables that potentially could affect enrollment and accumulation do not vary at the municipality level. We can therefore include fixed effects for the 532 municipalities in our data. Of course this problem will not deal with any omitted variable that may vary within the municipality if it is correlated with education accumulation or enrollment and varies across IDPS and other groups. Although we cannot readily think of a variable that fits this category that we have not controlled for directly or indirectly (income), we cannot rule out this possibility.

\section{Results}

\subsection{Does living in a high conflict area affect educational outcomes?}

The first question we try to answer as a motivation for our main set of questions is if living in a conflict region leads to a gap in education exposure. The purpose of this analysis is to compare our results to what has been noted in the prior literature using alternative datasets. Figure 4 shows the density function for the conflict index. We choose any municipality with conflict over 0.3 as a region 
Table 5: Does living in a conflict region affect educational outcomes?

\begin{tabular}{lcccc}
\hline \hline Variable: & \multicolumn{2}{c}{ Age 6-11 } & \multicolumn{2}{c}{ Age 12-17 } \\
\cline { 2 - 5 } & Accumulation Model & Enrollment Model & Accumulation Model & Enrollment Model \\
& $(1)$ & $(2)$ & $(3)$ & $(4)$ \\
\hline Conflict Region & $-0.036^{* * *}$ & $-0.008^{* * *}$ & $-0.036^{*}$ & $-0.009^{* *}$ \\
& $(0.01)$ & $(0.00)$ & $(0.02)$ & $(0.00)$ \\
Sex & $-0.132^{* * *}$ & $-0.009^{* * *}$ & $-0.493^{* * *}$ & $-0.042^{* * *}$ \\
& $(0.01)$ & $(0.00)$ & $(0.02)$ & $(0.00)$ \\
CAP & $0.165^{* * *}$ & 0.007 & $-0.237^{* * *}$ & $-0.022^{* *}$ \\
& $(0.03)$ & $(0.01)$ & $(0.06)$ & $(0.01)$ \\
Urban & 0.006 & $0.016^{* * *}$ & $0.457^{* * *}$ & $0.062^{* * *}$ \\
& $(0.01)$ & $(0.00)$ & $(0.02)$ & $(0.00)$ \\
Mom yrs of sch. & $0.044^{* * *}$ & $0.005^{* * *}$ & $0.109^{* * *}$ & $0.010^{* * *}$ \\
& $(0.00)$ & $(0.00)$ & $(0.00)$ & $(0.00)$ \\
Dad yrs of sch. & $0.019^{* * *}$ & $0.003^{* * *}$ & $0.055^{* * *}$ & $0.008^{* * *}$ \\
& $(0.00)$ & $(0.00)$ & $(0.00)$ & $(0.00)$ \\
\hline $\mathrm{N}$ & 171083 & 171393 & 148447 & 148650 \\
$\mathrm{~F}$ & 1794.31 & & 858.66 & \\
$P(F)>0$ & 0.000 & & 0.000 & 7443.67 \\
$R^{2}$ & 0.661 & 5672.32 & 0.472 & 0.000 \\
$\chi^{2}$ & & 0.000 & & 0.196 \\
$P>\chi^{2}$ & & 0.151 & & \\
Pseudo $R^{2}$ & & & & \\
\hline \hline
\end{tabular}

Note: Also controlled for age, race, family size, disability, employment status of father, automobile ownership, wall type, computer ownership, class of father's work, class of mother's work, mother's number of children, and department.

Note: ${ }^{*} p<0.05,{ }^{* *} p<0.01,{ }^{* * *} p<0.001$ 
with high conflict. The mean conflict index is 0.276 . Using this benchmark, $34.6 \%$ of the sample is exposed to high levels of conflict. We use this information to create a dummy variable which we include in our school accumulation and school enrollment models. Individuals with a conflict index more than 0.3 are assigned a 1 and everyone else is assigned a 0 . Controlling for the factors that can affect education accumulation or enrollment both on the individual and regional scale, the results in Table 5 indicate that children age 6-11 who live in a high conflict region have about 0.04 fewer years of schooling than those who do not. For the 12-17 year old children, the gap is larger (0.077) which is expected given the existence of a gap from elementary school. With respect to the probability of being enrolled, we note that children living in high conflict regions have a lower probability of being enrolled in school $(0.008 \%$ and $0.009 \%$ lower at the elementary and secondary school levels respectively). Our results are quite different from Rodriguez and Sanchez (2009) and much smaller. They find that without conflict, the average educational attainment of children between 6-11 years of age residing in conflict areas would have been 0.4 years larger, and for children between 12-17, 1.4 year larger. However differences in result is possible for several reasons. First, our result is comparing children in regions with high conflict to children in regions with lower conflict which is different from comparing high conflict with no conflict at all. Second, they make use of a duration model and look at the effect of past conflict on probability of dropping out and also joining the labor force using past exposure to conflict. In contrast, we are looking at the differences between children presently living in conflict region and those who are not. Also, they make use of the 2003 Colombia household survey covering 24,090 households between March and May 2003 in 128 municipalities. We make use of the 2005 census with a sample size of 2,003,186 and 533 municipalities. Our results seem to suggest that there is not much difference between children who live in regions with high conflict and those who do not. In fact, when we cluster our standard error given our conflict variable is at the municipality level, we get no significant effects in all cases apart from the probability of enrollment for children age 6-11years.

It is also important to mention that our estimate could be biased because of the possible endogenous nature of the living in a conflict area dummy. If living in a conflict area is correlated with an omitted variable that can affect education accumulation or enrollment, then the estimated coefficient could be biased. Although we control for many variables that could fit this profile with our capacity index, ${ }^{15}$ as noted by Rodriguez and Sanchez (2009), pressure to join militant groups is high in regions with high conflict and this could lead to lower school attainment or enrollment.

\footnotetext{
${ }^{15}$ The capacity index is a measure of a municipalities' infrastructure. We also tried alternative models with more poverty correlates like home ownership, floor type, number of rooms and the result does not change significantly. Given this result for the rest of the paper we restrict our selves to just a few poverty correlates.
} 
Hence, if we do not control for this omitted variable, we could attribute to living in a conflict region the impact of the pressure to join militant groups. Assuming this is true and given the negative correlation between pressure to join a militant group and attainment and enrollment, our estimated impact of living in a conflict region could be upward biased, implying an even smaller gap between children living in conflict region and children who do not. Another way to interpret these results is to think of the estimated impact as an upper limit on the difference as long as there is no omitted variable positively correlated with the $\mathrm{Y}$ variable and exposure to conflict. ${ }^{16}$ The above results suggest very little impact of living in a high conflict region in comparison to living in a municipality with less than average conflict. We investigate next whether directly being impacted by conflict leads to a similar outcome.

The above look at just the impact of living in a conflict region leads us to the main questions of our paper. What is the enrollment and education gap for the displaced? As highlighted in our model specification, we estimate an OLS regression controlling for potential heteroskedasticity and controlling for the general predictors of school accumulation. For our enrollment model, we estimate a probit model deriving the marginal effects. In both cases we divide the population into subgroups: non-recent migrants, and recent migrants, who we divide based on their primary reason for migrating. This creates eight dummy variables of migrant groups: migrants for work, family reasons, study natural disaster, health, other reasons, non-specificated and our group of interest IDPs (migrants because of violence). The base group we are comparing these groups with are those who did not migrate in the last five years.

\subsection{Results : School Accumulation Models}

The results summarized in Tables 6- 10 help us answer the question of whether there an education accumulation and enrollment gap for the children of those directly affected by conflict in comparison to other migrant sub-groups? Specifically, Table 6 summarizes the results from our estimation of the school accumulation models based on equation (1), for ages 6-11, using ordinary least squares (OLS) and correcting for potential heteroscedasticity. We highlight the other control variables included in our estimation under the table.

In column one we control for age, sex, race, family size, sector (urban or rural), disability, employment status of father, class of work of father, class of work of mother, years of school of mother, year of school of father, number of children of mother, and state of residence. We also include some proxies for wealth given the census data does not have information on income. There were several potential variable that we could use as proxies. Our choice reflected variables that we

\footnotetext{
${ }^{16}$ We could not think of any such variable that we did not control for but it is still a possibility.
} 
Table 6: Linear Regression Model Ages 6-11: Do migrants who move because of Violence and Insecurity face an attainment gap compared to non-migrants?

\begin{tabular}{|c|c|c|c|c|c|c|}
\hline & (1) & (2) & (3) & (4) & (5) & (6) \\
\hline & All & All & All & State & municipality & municipality \\
\hline & municipalities & municipalities & municipalities & conflict $>0.3$ & conflict $>0.3$ & conflict $>0.5$ \\
\hline \multirow{2}{*}{ "Work } & $\overline{-0.132^{* * *}}$ & 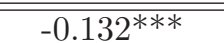 & $=0.131^{* * *}$ & $\begin{array}{c}-0.195^{* * *} \\
\end{array}$ & 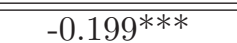 & 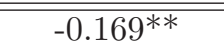 \\
\hline & $(0.03)$ & $(0.03)$ & $(0.03)$ & $(0.04)$ & $(0.05)$ & $(0.08)$ \\
\hline \multirow{2}{*}{ Family move } & $-0.201^{* * *}$ & $-0.201^{* * *}$ & $-0.200^{* * *}$ & $-0.218^{* * *}$ & $-0.213^{* * *}$ & $-0.228^{* * *}$ \\
\hline & $(0.01)$ & $(0.01)$ & $(0.01)$ & $(0.02)$ & $(0.02)$ & $(0.03)$ \\
\hline \multirow[t]{2}{*}{ Study } & -0.037 & -0.037 & -0.039 & -0.079 & -0.052 & -0.085 \\
\hline & $(0.05)$ & $(0.05)$ & $(0.05)$ & $(0.07)$ & $(0.07)$ & $(0.10)$ \\
\hline \multirow[t]{2}{*}{ Violence } & $-0.199 * * *$ & $-0.199 * * *$ & $-0.197 * * *$ & $-0.242^{* * *}$ & $-0.218^{* * *}$ & $-0.322^{* * *}$ \\
\hline & $(0.04)$ & $(0.04)$ & $(0.04)$ & $(0.05)$ & $(0.06)$ & $(0.09)$ \\
\hline \multirow[t]{2}{*}{ Nat. disaster } & $-0.134^{* * *}$ & $-0.134^{* * *}$ & $-0.134^{* * *}$ & $-0.184 * * *$ & -0.074 & -0.146 \\
\hline & $(0.05)$ & $(0.05)$ & $(0.05)$ & $(0.07)$ & $(0.07)$ & $(0.10)$ \\
\hline \multirow{2}{*}{ Health } & $-0.124^{* *}$ & $-0.124^{* *}$ & $-0.124^{* *}$ & -0.132 & -0.052 & -0.095 \\
\hline & $(0.06)$ & $(0.06)$ & $(0.06)$ & $(0.10)$ & $(0.12)$ & $(0.18)$ \\
\hline \multirow[t]{2}{*}{ Other } & $-0.186^{* * *}$ & $-0.187 * * *$ & $-0.185^{* * *}$ & $-0.212^{* * *}$ & $-0.164^{* * *}$ & $-0.150^{* * *}$ \\
\hline & $(0.02)$ & $(0.02)$ & $(0.02)$ & $(0.03)$ & $(0.04)$ & $(0.05)$ \\
\hline \multirow[t]{2}{*}{ Not specified } & -0.106 & -0.105 & -0.097 & -0.133 & -0.081 & -0.073 \\
\hline & $(0.09)$ & $(0.09)$ & $(0.09)$ & $(0.13)$ & $(0.14)$ & $(0.16)$ \\
\hline \multirow[t]{2}{*}{ Sex } & $-0.133^{* * *}$ & $-0.133^{* * *}$ & $-0.133^{* * *}$ & $-0.149 * * *$ & $-0.164^{* * *}$ & $-0.143^{* * *}$ \\
\hline & $(0.01)$ & $(0.01)$ & $(0.01)$ & $(0.01)$ & $(0.02)$ & $(0.02)$ \\
\hline \multirow[t]{2}{*}{ Urban } & $0.018^{*}$ & $0.018^{*}$ & $0.022^{* *}$ & 0.017 & 0.023 & 0.039 \\
\hline & $(0.01)$ & $(0.01)$ & $(0.01)$ & $(0.02)$ & $(0.02)$ & $(0.03)$ \\
\hline \multirow[t]{2}{*}{ Mom yrs of sch. } & $0.044^{* * *}$ & $0.044^{* * *}$ & $0.044^{* * *}$ & $0.050^{* * *}$ & $0.049^{* * *}$ & $0.051^{* * *}$ \\
\hline & $(0.00)$ & $(0.00)$ & $(0.00)$ & $(0.00)$ & $(0.00)$ & $(0.00)$ \\
\hline \multirow[t]{2}{*}{ Dad yrs of sch. } & $0.020 * * *$ & $0.020 * * *$ & $0.020^{* * *}$ & $0.018^{* * *}$ & $0.022^{* * *}$ & $0.024^{* * *}$ \\
\hline & $(0.00)$ & $(0.00)$ & $(0.00)$ & $(0.00)$ & $(0.00)$ & $(0.00)$ \\
\hline \multirow[t]{2}{*}{ Conflict } & & -0.012 & $-0.060^{* *}$ & -0.005 & -0.015 & 0.074 \\
\hline & & $(0.02)$ & $(0.02)$ & $(0.03)$ & $(0.04)$ & $(0.08)$ \\
\hline \multirow[t]{2}{*}{ CAP } & & & $0.145^{* * *}$ & $0.167^{* * *}$ & $0.264^{* * *}$ & $0.209^{* * *}$ \\
\hline & & & $(0.03)$ & $(0.04)$ & $(0.05)$ & $(0.06)$ \\
\hline $\mathrm{N}$ & 171083 & 171083 & 171083 & 74212 & 56722 & 28071 \\
\hline $\mathrm{F}$ & 1677.81 & 1657.45 & 1635.96 & 974.04 & 599.17 & 300.38 \\
\hline$P(F)>0$ & 0.000 & 0.000 & 0.000 & 0.000 & 0.000 & 0.000 \\
\hline$R^{2}$ & 0.663 & 0.663 & 0.663 & 0.665 & 0.649 & 0.641 \\
\hline
\end{tabular}

Note: Also controlled for age, race, family size, disability, employment status of father, automobile ownership, wall type, computer ownership, class of father's work, class of mother's work, mother's number of children, and department.

Note: ${ }^{*} p<0.05,{ }^{* *} p<0.01,{ }^{* * *} p<0.001$ 
believe could do a better job of capturing variation in wealth. These variables are number of cars, if an individual has a computer, and the type of walls of residence of an individual. ${ }^{17}$ Although we are interested in the accumulation gap for IDPs in comparison to non-recent migrants, we also present the marginal effects for other recent migrant groups. ${ }^{18}$ The results in column (1) do not control for conflict in the municipality or the social capacity in the municipality. Hence, estimates may exhibit upward bias. These result suggests that children of IDPs between the age of 6-11 (elementary school) have approximately 0.2 less years of schooling than non-migrants (approx $1 / 5$ of a year). When we control for conflict in the municipality, we do not notice any change in the schooling investment gap between children of IDPs and non-migrants (Table (6) column (2)). In the model captured in column (3), we control for capacity, which is a necessary control for school accumulation to reduce omitted variable bias in the estimate of the impact of conflict. Our dummy of interest does not differ considerably in column (3) from the 2 previous models. However, notice that the conflict variable is negative and significant, and the capacity variable is positive. Our measurement of the direct impact of conflict as captured by the gap between IDPs and non-migrants suggests a smaller effect than that found in Rodriguez and Sanchez (2007) focusing on exposure to conflict. They find about 0.4 years lower for children exposed to conflict (via in a conflict area) in contrast we find 0.2 less years of schooling for IDPs in comparison to non-migrants. As mentioned above, this differences is not totally unexpected. Our lower estimate may be due to differences in technique or approach and possibly due to the fact that some non-migrants could also have been exposed to conflict and so a gap between IDP and non-migrants would be smaller than a gap between IDP and those not exposed to conflict assuming exposure is important. Notice that this gap is much bigger than the estimated gap in the model summarized in Table 5. This difference suggests that living in a high conflict region may lead to a slightly lower school attainment, but it is not as important for education accumulation of children 6-11 years old as is being directly affected by conflict. Notice our $R^{2}$ are relatively high, meaning our model is explaining between $60-65 \%$ of the variation in school accumulation for children 6-11 years. Also recall that this estimated gap may form an upper limit to the potential accumulation gap if pressure to drop out of school is significant.

In Table 7, we summarize the results of similar models as in Table 6 but we restrict the sample to older children aged 12-17. The trend in the estimates is the same. Although our $R^{2}$ drops, it is still relatively high. Focusing on column (3), our results suggests that children of IDPs ages 12-17 have about half a year gap in education accumulation in comparison to non-migrants. Notice that

\footnotetext{
${ }^{17}$ We chose these three proxy for wealth but our results for IDPs do not change significantly with alternative choice combination of potential wealth proxies like type of floor, having a toilet, ownership of dwelling and so on.

${ }^{18}$ For the rest of the paper, we will refer to non-recent migrants as non-migrants.
} 
Table 7: Linear Ages 12-17: Do migrants who move because of Violence and Insecurity face attainment gaps compared to non-migrants?

\begin{tabular}{|c|c|c|c|c|c|c|}
\hline & (1) & (2) & (3) & (4) & (5) & (6) \\
\hline & All & All & All & State & municipality & municipality \\
\hline & municipalities & municipalities & municipalities & conflict $>0.3$ & conflict $>0.3$ & conflict $>0.5$ \\
\hline \multirow[t]{2}{*}{ Work } & $-0.453^{* * *}$ & $-0.453^{* * *}$ & $-0.454^{* * *}$ & $-0.459^{* * *}$ & $-0.468^{* * *}$ & -0.200 \\
\hline & $(0.06)$ & $(0.06)$ & $(0.06)$ & $(0.09)$ & $(0.12)$ & $(0.13)$ \\
\hline \multirow[t]{2}{*}{ Family } & $-0.229^{* * *}$ & $-0.230^{* * *}$ & $-0.232^{* * *}$ & $-0.263^{* * *}$ & $-0.252^{* * *}$ & $-0.206^{* * *}$ \\
\hline & $(0.03)$ & $(0.03)$ & $(0.03)$ & $(0.04)$ & $(0.05)$ & $(0.07)$ \\
\hline \multirow[t]{2}{*}{ Study } & 0.063 & 0.064 & 0.065 & $-0.183^{*}$ & -0.042 & 0.013 \\
\hline & $(0.08)$ & $(0.08)$ & $(0.08)$ & $(0.11)$ & $(0.14)$ & $(0.17)$ \\
\hline \multirow[t]{2}{*}{ Violence } & $-0.513^{* * *}$ & $-0.513^{* * *}$ & $-0.515^{* * *}$ & $-0.445^{* * *}$ & $-0.560 * * *$ & $-0.610^{* * *}$ \\
\hline & $(0.09)$ & $(0.09)$ & $(0.09)$ & $(0.12)$ & $(0.13)$ & $(0.19)$ \\
\hline \multirow[t]{2}{*}{ Nat. disaster } & $-0.279^{*}$ & $-0.279 *$ & $-0.281 *$ & -0.069 & -0.002 & -0.024 \\
\hline & $(0.15)$ & $(0.15)$ & $(0.15)$ & $(0.15)$ & $(0.18)$ & $(0.15)$ \\
\hline \multirow[t]{2}{*}{ Health } & $-0.458^{* * *}$ & $-0.458^{* * *}$ & $-0.457^{* * *}$ & -0.095 & $-0.350^{*}$ & -0.378 \\
\hline & $(0.12)$ & $(0.12)$ & $(0.12)$ & $(0.18)$ & $(0.19)$ & $(0.30)$ \\
\hline \multirow[t]{2}{*}{ Other } & $-0.218^{* * *}$ & $-0.220 * * *$ & $-0.222^{* * *}$ & $-0.213^{* * *}$ & $-0.186^{* *}$ & -0.160 \\
\hline & $(0.04)$ & $(0.04)$ & $(0.04)$ & $(0.06)$ & $(0.07)$ & $(0.11)$ \\
\hline \multirow{2}{*}{ Not spec } & $-0.713^{* * *}$ & $-0.712^{* * *}$ & $-0.722^{* * *}$ & $-0.760 * *$ & -0.130 & -0.407 \\
\hline & $(0.22)$ & $(0.22)$ & $(0.22)$ & $(0.31)$ & $(0.28)$ & $(0.45)$ \\
\hline \multirow[t]{2}{*}{ Sex } & $-0.495^{* * *}$ & $-0.495^{* * *}$ & $-0.494 * * *$ & $-0.512^{* * *}$ & $-0.503^{* * *}$ & $-0.534^{* * *}$ \\
\hline & $(0.02)$ & $(0.02)$ & $(0.02)$ & $(0.02)$ & $(0.03)$ & $(0.04)$ \\
\hline \multirow[t]{2}{*}{ Urban } & $0.477^{* * *}$ & $0.478^{* * *}$ & $0.472^{* * *}$ & $0.565^{* * *}$ & $0.521^{* * *}$ & $0.526^{* * *}$ \\
\hline & $(0.02)$ & $(0.02)$ & $(0.02)$ & $(0.03)$ & $(0.04)$ & $(0.05)$ \\
\hline \multirow[t]{2}{*}{ Mom yrs of sch. } & $0.108^{* * *}$ & $0.108^{* * *}$ & $0.108^{* * *}$ & $0.107^{* * *}$ & $0.113^{* * *}$ & $0.108^{* * *}$ \\
\hline & $(0.00)$ & $(0.00)$ & $(0.00)$ & $(0.00)$ & $(0.00)$ & $(0.01)$ \\
\hline \multirow[t]{2}{*}{ Dad yrs of sch. } & $0.056^{* * *}$ & $0.056^{* * *}$ & $0.056^{* * *}$ & $0.058^{* * *}$ & $0.063^{* * *}$ & $0.077^{* * *}$ \\
\hline & $(0.00)$ & $(0.00)$ & $(0.00)$ & $(0.00)$ & $(0.00)$ & $(0.01)$ \\
\hline \multirow[t]{2}{*}{ Conflict } & & $-0.148^{* * *}$ & -0.067 & -0.036 & $-0.127^{*}$ & 0.131 \\
\hline & & $(0.04)$ & $(0.04)$ & $(0.05)$ & $(0.07)$ & $(0.15)$ \\
\hline \multirow{2}{*}{ CAP } & & & $-0.250^{* * *}$ & $-0.234^{* * *}$ & -0.083 & 0.030 \\
\hline & & & $(0.06)$ & $(0.08)$ & $(0.09)$ & $(0.12)$ \\
\hline $\mathrm{N}$ & 148447 & 148447 & 148447 & 64052 & 48081 & 23326 \\
\hline $\mathrm{F}$ & 795.21 & 785.77 & 777.69 & & 305.98 & 172.02 \\
\hline$P(F)>0$ & 0.000 & 0.000 & 0.000 & & 0.000 & 0.000 \\
\hline$R^{2}$ & 0.474 & 0.474 & 0.474 & 0.476 & 0.476 & 0.487 \\
\hline
\end{tabular}


this gap is bigger than the gap for the children of all the other migrant groups apart from those who migrated for non specified reasons. Also note that this gap is not directly comparable to the results of Rodriguez and Sanchez (2007), who find exposure to conflict leads to one year less of schooling. This is because we are estimating the impact of being directly affected by conflict in comparison to non-migrants who are not. In contrast they look at the impact of exposure to conflict. ${ }^{19}$

\subsection{Results: School Enrollment Models}

We move away from our education accumulation model and check to see if our enrollment model leads to similar conclusions as above. First, we estimate the probability of being enrolled in school for children 6-11 years (Table 8) and afterwards, we re-estimate our accumulation model for children ages 12-17 (Table 9). In contrast to the accumulation model for which we present estimates, for our enrollment model, in Tables 8 and 9 we present the marginal effects from the probit model estimation. The results in column (3), our preferred model, suggest that children of IDPs are $1.6 \%$ less likely to be enrolled in school in comparison to non-migrants. In Table 8, the marginal effects for the children ages 12-17 using the different alternations to the enrollment model are summarized.

The results for older children indicate an increase in the enrollment gap compared to younger children. Specifically looking at the whole population, children of IDPs ages 12-17 are 6.3\% less likely to be enrolled in school than are the children of non-migrants. This gap is significant, and one way to put it in perspective is to look at the gap for other migrant groups. Given that we do not control for selectivity of these migrant groups, it is possible that the estimates will be upward biased. Hence we can think of these estimates as an upper limit on the education enrollment gaps for these migrant groups. Notice however that the gap even for secondary school aged children of those who migrate for work, natural disaster, or health, is smaller than the gap for children whose parents were directly affected by conflict. For the children 6-11 years, there is not much difference in enrollment for most migrant groups compared to non-migrants. Notice from Table 8 that the enrollment gap is even slightly larger for children of migrants for health reasons and work. This finding is in line with Rodriguez and Sanchez (2007), who find much larger effects of exposure to conflict at the secondary level versus the primary level.

The results above raise question on what are the possible channels through which direct contact with conflict can lead to lower education accumulation. Those who are directly impacted by conflict sometimes lose their assets or sources of income, which may create a constraint on future income streams and expenditures, including expenditure on children's education. However this cannot be the only channel because those who migrate because of natural diaster are also likely to have lost

\footnotetext{
${ }^{19}$ Our base group non-migrant have not been directly affected by conflict, but could have been exposed to conflict.
} 
Table 8: Probit Model Ages 6-11: Do migrants who move because of Violence and Insecurity face attainment and enrollment gaps compared to non-migrants?

\begin{tabular}{|c|c|c|c|c|c|c|}
\hline & (1) & (2) & (3) & (4) & (5) & (6) \\
\hline & All & All & All & State & municipality & municipality \\
\hline & municipalities & municipalities & municipalities & conflict $>0.3$ & conflict $>0.3$ & conflict $>0.5$ \\
\hline \multirow[t]{2}{*}{ "Work } & 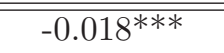 & $\overline{-0.018^{* * *}}$ & "-0.018*** & $-0.027^{* *}$ & $-0.031^{* *}$ & -0.021 \\
\hline & $(0.01)$ & $(0.01)$ & $(0.01)$ & $(0.01)$ & $(0.01)$ & $(0.02)$ \\
\hline \multirow[t]{2}{*}{ Family move } & 0.003 & 0.003 & 0.003 & 0.004 & 0.003 & 0.000 \\
\hline & $(0.00)$ & $(0.00)$ & $(0.00)$ & $(0.00)$ & $(0.01)$ & $(0.01)$ \\
\hline \multirow[t]{2}{*}{ Study } & 0.006 & 0.006 & 0.006 & $0.023^{* * *}$ & $0.020^{* *}$ & $0.024^{* *}$ \\
\hline & $(0.01)$ & $(0.01)$ & $(0.01)$ & $(0.01)$ & $(0.01)$ & $(0.01)$ \\
\hline \multirow[t]{2}{*}{ Violence } & $-0.017^{*}$ & $-0.016^{*}$ & $-0.016^{*}$ & -0.012 & -0.019 & $-0.033^{*}$ \\
\hline & $(0.01)$ & $(0.01)$ & $(0.01)$ & $(0.01)$ & $(0.01)$ & $(0.02)$ \\
\hline \multirow[t]{2}{*}{ Nat. disaster } & -0.006 & -0.007 & -0.007 & 0.013 & 0.001 & 0.014 \\
\hline & $(0.01)$ & $(0.01)$ & $(0.01)$ & $(0.01)$ & $(0.01)$ & $(0.01)$ \\
\hline \multirow[t]{2}{*}{ Health } & $-0.026^{*}$ & $-0.026^{*}$ & $-0.026^{*}$ & -0.041 & -0.037 & -0.035 \\
\hline & $(0.02)$ & $(0.02)$ & $(0.02)$ & $(0.03)$ & $(0.04)$ & $(0.05)$ \\
\hline \multirow[t]{2}{*}{ Other } & 0.003 & 0.003 & 0.003 & 0.006 & 0.015 & 0.001 \\
\hline & $(0.01)$ & $(0.01)$ & $(0.01)$ & $(0.01)$ & $(0.01)$ & $(0.02)$ \\
\hline \multirow[t]{2}{*}{ Not specified } & $-0.065^{* * *}$ & $-0.063^{* * *}$ & $-0.062^{* * *}$ & $-0.065^{* * *}$ & -0.019 & -0.016 \\
\hline & $(0.02)$ & $(0.02)$ & $(0.02)$ & $(0.03)$ & $(0.02)$ & $(0.03)$ \\
\hline \multirow[t]{2}{*}{ Sex } & $-0.009 * * *$ & $-0.009^{* * *}$ & $-0.009 * * *$ & $-0.007^{* *}$ & $-0.009 * * *$ & -0.005 \\
\hline & $(0.00)$ & $(0.00)$ & $(0.00)$ & $(0.00)$ & $(0.00)$ & $(0.00)$ \\
\hline \multirow[t]{2}{*}{ Urban } & $0.015^{* * *}$ & $0.015^{* * *}$ & $0.016^{* * *}$ & $0.017^{* * *} *$ & $0.022 * * *$ & $0.031^{* * *}$ \\
\hline & $(0.00)$ & $(0.00)$ & $(0.00)$ & $(0.00)$ & $(0.00)$ & $(0.00)$ \\
\hline \multirow[t]{2}{*}{ Mom yrs of sch. } & $0.005^{* * *}$ & $0.005^{* * *}$ & $0.005^{* * *}$ & $0.006^{* * *}$ & $0.006^{* * *}$ & $0.007^{* * *}$ \\
\hline & $(0.00)$ & $(0.00)$ & $(0.00)$ & $(0.00)$ & $(0.00)$ & $(0.00)$ \\
\hline \multirow[t]{2}{*}{ Dad yrs of sch. } & $0.003^{* * *}$ & $0.003^{* * *}$ & $0.003^{* * *}$ & $0.003^{* * *}$ & $0.004^{* * *}$ & $0.003^{* * *}$ \\
\hline & $(0.00)$ & $(0.00)$ & $(0.00)$ & $(0.00)$ & $(0.00)$ & $(0.00)$ \\
\hline \multirow[t]{2}{*}{$\mathrm{CONF}$} & & $-0.017^{* * *}$ & $-0.021 * * *$ & $-0.022^{* * *}$ & $-0.029 * * *$ & $-0.038^{* * *}$ \\
\hline & & $(0.00)$ & $(0.00)$ & $(0.01)$ & $(0.01)$ & $(0.01)$ \\
\hline \multirow[t]{2}{*}{ CAP } & & & $0.012^{* *}$ & 0.006 & $0.022^{* *}$ & $0.028^{* *}$ \\
\hline & & & $(0.01)$ & $(0.01)$ & $(0.01)$ & $(0.01)$ \\
\hline $\mathrm{N}$ & 171393 & 171393 & 171393 & 74322 & 56835 & 28136 \\
\hline$\chi^{2}$ & 5699.98 & 5722.44 & 5709.09 & 2096.64 & 2580.28 & 1421.15 \\
\hline$P>\chi^{2}$ & 0.000 & 0.000 & 0.000 & 0.000 & 0.000 & 0.000 \\
\hline Pseudo $R^{2}$ & 0.151 & 0.152 & 0.152 & 0.143 & 0.174 & 0.180 \\
\hline
\end{tabular}

Note: Also controlled for age, race, family size, disability, employment status of father, automobile ownership, wall type, computer ownership, class of father's work, class of mother's work, mother's number of children, and department.

Note: ${ }^{*} p<0.05,{ }^{* *} p<0.01,{ }^{* * *} p<0.001$ 
Table 9: Probit Model Ages 12-17: Do migrants who move because of Violence and Insecurity face attainment and enrollment gaps compared to non-migrants?

\begin{tabular}{|c|c|c|c|c|c|c|}
\hline & (1) & (2) & (3) & (4) & (5) & (6) \\
\hline & All & All & All & State & municipality & municipality \\
\hline & municipalities & municipalities & municipalities & conflict $>0.3$ & conflict $>0.3$ & conflict $>0.5$ \\
\hline \multirow{2}{*}{ "Work } & $-0.045^{* * *}$ & $-0.045^{* * *}$ & $-0.045^{* * *}$ & $-0.045^{* * *}$ & $-0.036^{* *}$ & "-0.007 \\
\hline & $(0.01)$ & $(0.01)$ & $(0.01)$ & $(0.02)$ & $(0.02)$ & $(0.02)$ \\
\hline \multirow[t]{2}{*}{ Family } & -0.009 & -0.009 & -0.010 & -0.012 & -0.005 & -0.006 \\
\hline & $(0.01)$ & $(0.01)$ & $(0.01)$ & $(0.01)$ & $(0.01)$ & $(0.02)$ \\
\hline \multirow[t]{2}{*}{ Study } & 0.007 & 0.007 & 0.007 & 0.037 & 0.036 & 0.047 \\
\hline & $(0.02)$ & $(0.02)$ & $(0.02)$ & $(0.02)$ & $(0.02)$ & $(0.03)$ \\
\hline \multirow[t]{2}{*}{ Violence } & $-0.063^{* * *}$ & $-0.063^{* * *}$ & $-0.063^{* * *}$ & $-0.060 * * *$ & $-0.105^{* * *}$ & $-0.107^{* *}$ \\
\hline & $(0.02)$ & $(0.02)$ & $(0.02)$ & $(0.02)$ & $(0.03)$ & $(0.05)$ \\
\hline \multirow[t]{2}{*}{ Nat. disaster } & -0.025 & -0.025 & -0.025 & -0.020 & -0.034 & -0.039 \\
\hline & $(0.02)$ & $(0.02)$ & $(0.02)$ & $(0.03)$ & $(0.03)$ & $(0.04)$ \\
\hline \multirow[t]{2}{*}{ Health } & $-0.028^{*}$ & $-0.028^{*}$ & $-0.028^{*}$ & $-0.070^{* *}$ & -0.029 & -0.015 \\
\hline & $(0.02)$ & $(0.02)$ & $(0.02)$ & $(0.03)$ & $(0.03)$ & $(0.04)$ \\
\hline \multirow[t]{2}{*}{ Other } & 0.005 & 0.005 & 0.004 & 0.002 & 0.010 & 0.019 \\
\hline & $(0.01)$ & $(0.01)$ & $(0.01)$ & $(0.02)$ & $(0.02)$ & $(0.02)$ \\
\hline \multirow[t]{2}{*}{ Not spec } & -0.050 & -0.050 & -0.051 & -0.012 & 0.018 & -0.070 \\
\hline & $(0.04)$ & $(0.04)$ & $(0.04)$ & $(0.05)$ & $(0.05)$ & $(0.08)$ \\
\hline Sex & $\begin{array}{c}-0.042^{* * *} \\
(0.00)\end{array}$ & $\begin{array}{c}-0.042^{* * *} \\
(0.00)\end{array}$ & $\begin{array}{c}-0.042^{* * *} \\
(0.00)\end{array}$ & $\begin{array}{c}-0.053^{* * *} \\
(0.00)\end{array}$ & $\begin{array}{c}-0.049^{* * *} \\
(0.01)\end{array}$ & $\begin{array}{c}-0.047^{* * *} \\
(0.01)\end{array}$ \\
\hline \multirow[t]{2}{*}{ Urban } & $0.062^{* * *}$ & $0.063^{* * *}$ & $0.062^{* * *}$ & $0.081^{* * *}$ & $0.075^{* * *}$ & $0.075^{* * *}$ \\
\hline & $(0.00)$ & $(0.00)$ & $(0.00)$ & $(0.00)$ & $(0.01)$ & $(0.01)$ \\
\hline \multirow[t]{2}{*}{ Mom yrs of sch. } & $0.010^{* * *}$ & $0.010^{* * *}$ & $0.010^{* * *}$ & $0.010^{* * *}$ & $0.009 * * *$ & $0.010^{* * *}$ \\
\hline & $(0.00)$ & $(0.00)$ & $(0.00)$ & $(0.00)$ & $(0.00)$ & $(0.00)$ \\
\hline \multirow[t]{2}{*}{ Dad yrs of sch. } & $0.008^{* * *}$ & $0.008^{* * *}$ & $0.008^{* * *}$ & $0.008^{* * *}$ & $0.008^{* * *}$ & $0.008^{* * *}$ \\
\hline & $(0.00)$ & $(0.00)$ & $(0.00)$ & $(0.00)$ & $(0.00)$ & $(0.00)$ \\
\hline \multirow[t]{2}{*}{$\mathrm{CONF}$} & & $-0.025^{* * *}$ & $-0.018^{* *}$ & $-0.022^{* *}$ & -0.013 & $0.052^{*}$ \\
\hline & & $(0.01)$ & $(0.01)$ & $(0.01)$ & $(0.01)$ & $(0.03)$ \\
\hline \multirow[t]{2}{*}{ CAP } & & & $-0.021^{* *}$ & $-0.033^{* *}$ & -0.016 & 0.021 \\
\hline & & & $(0.01)$ & $(0.01)$ & $(0.02)$ & $(0.02)$ \\
\hline $\mathrm{N}$ & 148650 & 148650 & 148650 & 64136 & 48171 & 23384 \\
\hline$\chi^{2}$ & 7366.80 & 7441.71 & 7444.77 & 3614.16 & 2679.77 & 1442.17 \\
\hline$P>\chi^{2}$ & 0.000 & 0.000 & 0.000 & 0.000 & 0.000 & 0.000 \\
\hline Pseudo $R^{2}$ & 0.196 & 0.196 & 0.196 & 0.195 & 0.191 & 0.192 \\
\hline
\end{tabular}

Note: Also controlled for age, race, family size, disability, employment status of father, automobile ownership, wall type, computer ownership, class of father's work, class of mother's work, mother's number of children, and department.

Note: ${ }^{*} p<0.05,{ }^{* *} p<0.01,{ }^{* * *} p<0.001$ 
assets and also be constrained on their expenditure. Yet, they do not have an education enrollment gap half as large as IDPs. Another possible channel is that being directly affected by conflict may lead to more members of the family getting maimed or even killed. Family members being disabled and killed could lead to reallocation of duties within a household and could lead to children being forced to drop out of school to care for the disabled member or going to work. This would be especially true if the family member was the household head or care giver. Table 1 shows that IDPs are more likely to be disabled, which is suggestive evidence in support of the second highlighted reason for the gap. Another reason beyond the scope of economics could be the psychological impact on children of being directly affected by conflict. There is research that shows that children who pass through traumatic experiences have lower education outcomes in general. If one combines this potential psychological effect with the two earlier highlighted channels and the education disruption that comes with having to move to another location for exogenous reasons, then the larger gap in education accumulation and enrollment for children of IDPs compared to non-migrants and everyone else would be expected.

\subsection{Results: Question 3}

To answer our third question, we further investigate if lower school attainment for IDPs is linked with being directly impacted by conflict, living in a high conflict area in the past, or a combination of both factors. We try to answer this question in several ways. Our hypothesis is that if the issue is more about simply living in a high conflict regions, then even those who do not migrate but live in a high conflict area should have similar levels of schooling as the IDPs who left the highconflict regions. Hence, if we restrict our sample to only those living in regions with high conflict, the estimate on the IDP dummy should be 0 or close to 0 . We explore three alternative ways of restricting the sample. Our conflict index runs from 0-1 with a mean of 0.28. In column (4) of Tables 6-9 we restrict ourself to states with a mean conflict of over 0.3. This analysis leads to a reduction in the sample of states in the analysis from 33 to 14 . We then re-estimate our original model on this sub-sample. The result of this estimation is summarized in column (4) in Tables 6-9. Focusing on Table 6 column (4), contrary to what may be expected, we find that children of IDPs living in high conflict states have a 0.24 years less school attainment than children of non-migrants who live in high conflict states. However, averaging over the state may be misleading. Restricting the sample based on high conflict municipalities versus high conflict states may be more informative. In columns (5) and (6) of Tables 6-9, we restrict the sample to only those living in municipalities with a conflict index greater than 0.3 and 0.5 respectively. We still find that children of IDPs living in high conflict areas have a lower school attainment (Tables 6 and 7 ) and lower school enrollment 
(Table s8 and 9 ). Specifically, we find that children of IDPs who are 6-11 years living in high conflict regions have a 0.22 years lower level of school attainment and have a $1.9 \%$ lower probability of being enrolled in school in compared to non-migrants living in high conflict regions. For children of IDPs 12-17, the gap is significantly greater: 0.56 less years of schooling and a $10.3 \%$ lower probability of being enrolled in school.

It is worth noting from Tables 6 and 7 that the gap in education accumulation increases when we focus on municipality with really intense conflict (index $>0.5$ ). For ages $6-11$, the gap increases to 0.32 years while for ages $12-17$, the gap increases to 0.61 years. We note a similar increase in the probability of not being in school in the intense conflict municipalities (see Tables 8 and 9). We also note that the conflict variable in the education accumulation model is insignificant when we focus solely on high conflict areas. This finding suggests that beyond a threshold of conflict, when we control for capacity and other predictors of schooling, their is no effect of more conflict exposure on accumulation of schooling. Also, given the change in the education gap is minimal when we focus on high conflict municipalities who share similar pressure to leave school, then we can infer that the effect of the potential omitted variable bias linked with pressure to leave school if it exist, is minimal. We see similar trends in the results from our enrollment model.

These results combined with the results in Table 5 provide evidence that though exposure to conflict might affect education accumulation and enrollment for children, being directly affected by conflict impacts these outcomes more significantly. Therefore, living in a region with high conflict does not lead to the same education impact as being directly affected by conflict. However, it is possible to argue that the persistence of a gap between IDPs and other non-migrants living in the same high conflict region region suggests that IDPs living in high conflict regions are different from other IDPs and although exposure to conflict leads to lower school attainment, being an IDP who migrates to a high conflict municipality creates an extra impact. In this scenario, there would still be a gap between IDPs and others living in a high conflict region. In the next section we will address the question of whether IDPs living in high conflict regions are unique, explaining the education gap between children of this group and children of non-migrants living in high conflict communities.

\subsection{Results Question 4: Could IDPs be different from others living in a conflict regions}

The results we use to answer the question on how do IDPs compare to other other migrants in education accumulation and enrollment are summarized in Tables 10 and 11. Focusing on migrants could be useful for several reasons. First, it is possible to argue that IDPs are migrants and comparing them with migrants is more appropriate. Notice that in all the earlier tables, children of most 
migrant groups have lower accumulation and enrollment probabilities than non-migrants. Hence one could argue that the gap between IDPs children in high conflict regions and non-migrant children could be linked in part to the selection linked with migration. Though this argument has some credibility for most migrant groups, IDPs and natural disaster migrants are different because they move as a result of exogenous factors. For other migrant groups, we can argue that selectivity may be responsible for the gap between their education accumulation or probability of enrollment in comparison to non-migrants (see column (3) Table 6-9) because of the endogenous nature of their choice to migrate. For example, notice that children of migrants who migrated for study do not exhibit the gap other migrants groups exhibit. Again this is a reflection of the selectivity of these kind of migrants. On the other hand, migration of IDPs is linked with an exogenous shock just like those who migrate because of natural diasters. Although it may be safe to assume selectivity is not an issue for IDPs and migrants linked to disaster, as long as not all who are affected by these exogenous shocks migrate, we cannot fully rule out issues of selectivity.

Another related argument centered on migrants is that even if IDPs are not a select group like other kinds of migrants, the problem of migrants is really not about them being a select group with lower preference for education accumulation, but rather, it is the disruption that comes with migration. If migration leads to disruption in schooling that has a long lasting effect, then all migrants including IDPs will exhibit lower levels of educational attainment than non-migrants even if the municipality being considered is one of high conflict. The problem with this argument is that it does not hold for all groups of migrants. First, if there was no issue as it relates to selectivity in type for migrants and the effect of migration was limited to the disruption in schooling argument, then all migrants subgroups, ceteris paribus, should have similar gaps in enrollment and accumulation when compared to non-migrants. This is not what we find in Tables 6-9. The gap in accumulation and enrollment differs significantly across groups. Also, as mentioned above, our results suggest that in comparison to children of non-migrants, there is no education gap for children whose parents migrated for schooling reasons. The lack of a gap for this group suggests that the issue with migrants is not one caused largely by school disruption, but as mentioned earlier, is more of a selectivity issue with respect to types. If children of migrant groups are disadvantaged with respect to education accumulation and enrollment apart from those who migrated for school related reasons, then it would be interesting to find out if a gap would exist if we compare them as a group with children of IDPs who we have earlier highlighted also as being disadvantaged with respect to education accumulation and enrollment. This is the motivation for our final question. As highlighted in our empirical strategy, we focus this analysis first on recent migrants to make it comparable to recent 
Table 10: Are IDPs different? Ages 6-11

\begin{tabular}{|c|c|c|c|c|c|c|}
\hline \multirow[t]{3}{*}{ Variable: } & \multicolumn{3}{|c|}{ Education Accumulation Model } & \multicolumn{3}{|c|}{ School Enrollment Model } \\
\hline & All & Migrants & All obs & All & Migrants & All \\
\hline & $\begin{array}{l}\text { Migrants } \\
\text { (1) }\end{array}$ & $\begin{array}{c}\text { Conf }(>0.3) \\
(2)\end{array}$ & $\begin{array}{c}\text { with } \operatorname{Conf}(>0.3) \\
(3)\end{array}$ & $\begin{array}{l}\text { Migrants } \\
\text { (4) }\end{array}$ & $\begin{array}{c}\text { Conf }(>0.3) \\
(5)\end{array}$ & with $\operatorname{Conf}(>0.3)$ \\
\hline \multirow[t]{2}{*}{ IDP } & -0.042 & -0.067 & $-0.105^{* *}$ & -0.010 & $-0.022^{* *}$ & -0.008 \\
\hline & $(0.04)$ & $(0.06)$ & $(0.04)$ & $(0.01)$ & $(0.01)$ & $(0.01)$ \\
\hline \multirow[t]{2}{*}{ Sex } & $-0.101 * * *$ & $-0.131^{* * *}$ & $-0.166^{* * *}$ & $-0.010^{* * *}$ & $-0.012^{* *}$ & $-0.010^{* * *}$ \\
\hline & $(0.02)$ & $(0.03)$ & $(0.02)$ & $(0.00)$ & $(0.01)$ & $(0.00)$ \\
\hline \multirow[t]{2}{*}{ Conflict } & 0.011 & 0.007 & -0.023 & -0.009 & -0.019 & $-0.032^{* * *}$ \\
\hline & $(0.05)$ & $(0.08)$ & $(0.04)$ & $(0.01)$ & $(0.01)$ & $(0.01)$ \\
\hline \multirow[t]{2}{*}{ Capacity } & 0.044 & 0.138 & $0.286^{* * *}$ & 0.002 & 0.000 & $0.022^{* *}$ \\
\hline & $(0.07)$ & $(0.10)$ & $(0.05)$ & $(0.01)$ & $(0.02)$ & $(0.01)$ \\
\hline \multirow[t]{2}{*}{ Urban } & $0.044^{* *}$ & $0.075^{* *}$ & 0.009 & $0.014^{* * *}$ & $0.025^{* * *}$ & $0.023^{* * *}$ \\
\hline & $(0.02)$ & $(0.04)$ & $(0.02)$ & $(0.00)$ & $(0.01)$ & $(0.00)$ \\
\hline \multirow[t]{2}{*}{ Mom Yrs of sch. } & $0.037^{* * *}$ & $0.036^{* * *}$ & $0.049^{* * *}$ & $0.004^{* * *}$ & $0.004^{* * *}$ & $0.007 * * *$ \\
\hline & $(0.00)$ & $(0.01)$ & $(0.00)$ & $(0.00)$ & $(0.00)$ & $(0.00)$ \\
\hline \multirow[t]{2}{*}{ Dad Yrs of sch. } & $0.020^{* * *}$ & $0.027^{* * *}$ & $0.021^{* * *}$ & $0.003^{* * *}$ & $0.003^{* * *}$ & $0.003^{* * *}$ \\
\hline & $(0.00)$ & $(0.00)$ & $(0.00)$ & $(0.00)$ & $(0.00)$ & 0 \\
\hline $\mathrm{N}$ & 34457 & 11410 & 57815 & 34459 & 11428 & 57893 \\
\hline $\mathrm{F}$ & 453.48 & 170.13 & - & & & \\
\hline$P>(F)$ & 0.000 & 0.000 & - & & & \\
\hline$R^{2}$ & 0.700 & 0.684 & 0.647 & & & \\
\hline$\chi^{2}$ & & & & 1299.79 & 553.27 & 2541.03 \\
\hline$P>\left(\chi^{2}\right)$ & & & & 0.000 & 0.000 & 0.000 \\
\hline PseudoR ${ }^{2}$ & & & & 0.157 & 0.144 & 0.173 \\
\hline
\end{tabular}

Note: Also controlled for age, race, family size, disability, employment status of father, automobile ownership, wall type, computer ownership, class of father's work, class of mother's work, mother's number of children, and department.

$* p<0.05,{ }^{* *} p<0.01,{ }^{* * *} p<0.001$

Selection implies that we restricting the sample to all IDPs and both migrants and non-migrants leaving in region with high conflict.

IDPs. However we also compare the recent IDPs to anyone who has migrated over their lifetime. ${ }^{20}$ Table 10 summarizes the results for children 6-11 years and Table 11 summarizes the results for children 12-17 years.

In Tables 10 and 11, the results in columns (1) to (3) summarize the results using the education accumulation model, while the last three columns summarize the results using the probability model. In columns (1) and (4), we summarize the results using the sample of all migrants while in columns

\footnotetext{
${ }^{20}$ We are able to find other migrants apart from the recent migrants over the last five years highlighted in the census by comparing where in individual lives now to were they were born. If these two municipalities are different, we include this person in the sample. We then compare IDPs to the groups of all other migrants.
} 
(2) and (5) we restrict ourselves to the sub-sample of migrants living in municipalities with conflict index greater than 0.3. The results provides support for our earlier conclusion about the direct impact of conflict. We find that even when we compare IDPs to other migrants, who are a select group with lower education accumulation and enrollment than non-migrants, we still notice a gap for IDPs both in enrollment and accumulation for older children. ${ }^{21}$ However, we find that for children 6-11 years, the gap is negative but not significant in all cases but in column (5). However, if we extend the sample to all migrants-recent or not recent (see Table 17 in the appendix), we notice a small but statistically significant difference in accumulation and enrollment. In contrast, when we look at the older kids as in Table 11, the education gap is larger and statistically significant. The education accumulation gap for IDPs when compared to other migrants is about 0.35 years which is about 0.15 years less than the gap with non-migrants. With respect to enrollment, the gap is also less than if IDPs are compared with non-migrants but not by much. Children of IDPs are approximately $4.1 \%$ less likely to be enrolled in school when compared to other migrants, while $6.3 \%$ less likely if compared to non-migrants. The results from the analysis focused solely on migrants suggests that the education gap of children of IDPs is not a gap linked with being a migrant given the persistence of a gap when migrants are the sole focus of the analysis. Second, given that the gap between IDPs and migrants in most cases is smaller than the gap when IDPs are compared with nonmigrants, suggest that there might be some selection bias with respect to education accumulation and enrollment when we focus on migrants.

To address any potential selectivity bias that may arise in Table 6-9 column (4)-(6) when we compare IDPs to non-migrants living in high conflict areas, we restrict our migrants to those living in conflict areas and compare them to those directly affected by conflict. Given that both groups migrated to high conflict region, the original argument with respect to selectivity cannot be made. The results in Tables 10 and 11 columns (2) and (5) suggest that for children 6-11 years, there is no difference in educational accumulation between those whose who are directly affected by conflict and those who are exposed to conflict. However those who are directly affected by conflict have a $2.2 \%$ less probability of being enrolled in school. When we consider children $12-17$, the results are more consistent across both our accumulation and enrollment models. We find that children of IDPs have about 0.4 less years of schooling and are $8.8 \%$ less likely to be enrolled in school. This significant gap could suggest one of two things. First, living in a conflict region is only marginally important for education accumulation and enrollment, as noted in Table 5 and confirmed here.

\footnotetext{
${ }^{21}$ This gap is not created by children of migrants who move for study and are likely to have higher education outcomes than other migrants. To verify this we drop these children from our analysis but our estimated gap is not statistically different with or without them.
} 
What is important is being directly affected by conflict especially at the secondary level. Second, given that children of migrants living in high conflict areas still have better education outcomes than IDPs, the channel that leads to lower school accumulation and enrollment in IDPs cannot be explained largely by migration or disruption in schools because of living in a conflict area. Rather, loss of income of parents, lower probability of employment of parents or care givers who become disabled because of conflict, and psychological factors linked with being directly affected by conflict are more likely explanations for this gap.

In columns (3) and (6) of Tables 10 and 11, we compare all IDPs with those who live in high conflict regions. This is another robustness check to avoid the possible argument that when we compared IDPS in conflict regions with others in those regions, we might be dealing with a select type of IDP. This is because we will be focusing on IDPs who are supposed to have migrated for the sole reason to avoid conflict but still end up in a place with high conflict. This may suggest that such IDPs are highly vulnerable, have no other options and are different from other IDPs who do not migrate to a high conflict region. By comparing all IDPS whether or not they live in conflict regions with migrants and non-migrants who live in conflict region, we avoid this potential issue.

The results in columns (3) and (6) suggest that children of IDPs ages 6-11 have about 0.1 year less schooling than other children living in a high conflict region but similar probability of being enrolled in school. For children of IDPs ages 12-17, they have 0.44 fewer years of schooling than children of everyone else living in a high conflict region. They also have a 5.7\% lower probability of being enrolled. Given that the education gap shrunk when we compare all children of IDPs to other children living in high conflict regions, this suggests that IDPs living in a high conflict region are to some extent different from the average IDP.

\subsection{Robustness checks: Are the results driven by sampling bias}

All the analysis above suggests that being directly affected by conflict affects children's probability of being enrolled in school at both the elementary level and secondary level. It also affects their educational accumulation. However, the effect on younger children is smaller and not always significant. On the other hand, the gaps for older children are consistently significant and of higher magnitude. Although we find that some migrants on average have lower levels of educational accumulation and those who live in a high conflict region in general have slightly lower education accumulation and enrollment than those who do not live in such municipalities, the gap does not compare to that faced by IDPs. Despite the analysis above, it is possible to raise the question of whether this persisting gap in education attainment and enrollment for IDPs is driven by some omitted variable that is correlated with being directly affected by conflict. We are of the opinion that it is not for several 
Table 11: Are IDPs different? Ages 12-17

\begin{tabular}{|c|c|c|c|c|c|c|}
\hline \multirow[t]{3}{*}{ Variable: } & \multicolumn{3}{|c|}{ Education Accumulation Model } & \multicolumn{3}{|c|}{ School Enrollment Model } \\
\hline & All & Migrants & All obs & All & Migrants & All \\
\hline & $\begin{array}{l}\text { Migrants } \\
\text { (1) }\end{array}$ & $\begin{array}{c}\text { Conf }(>0.3) \\
(2)\end{array}$ & $\begin{array}{c}\text { with } \operatorname{Conf}(>0.3) \\
(3)\end{array}$ & $\begin{array}{l}\text { Migrants } \\
\text { (4) }\end{array}$ & $\begin{array}{c}\text { Conf }(>0.3) \\
(5)\end{array}$ & $\begin{array}{c}\text { with } \operatorname{Conf}(>0.3) \\
(6)\end{array}$ \\
\hline \multirow[t]{2}{*}{ IDP } & $-0.341^{* * *}$ & $-0.395^{* * *}$ & $-0.443^{* * *}$ & $-0.041^{* * *}$ & $-0.088^{* * *}$ & $-0.057^{* * *}$ \\
\hline & $(0.09)$ & $(0.14)$ & $(0.09)$ & $(0.02)$ & $(0.03)$ & $(0.02)$ \\
\hline \multirow[t]{2}{*}{ Sex } & $-0.427 * * *$ & $-0.429^{* * *}$ & $-0.506^{* * *}$ & $-0.029 * * *$ & $-0.039 * * *$ & $-0.050^{* * *}$ \\
\hline & (0.03) & $(0.06)$ & $(0.03)$ & $(0.01)$ & $(0.01)$ & $(0.01)$ \\
\hline \multirow[t]{2}{*}{ Conflict } & -0.030 & 0.015 & $-0.131 *$ & -0.014 & -0.020 & -0.019 \\
\hline & $(0.10)$ & $(0.17)$ & $(0.07)$ & $(0.02)$ & $(0.03)$ & $(0.01)$ \\
\hline \multirow[t]{2}{*}{ Capacity } & $-0.305^{* *}$ & $-0.404^{*}$ & -0.054 & -0.032 & -0.005 & -0.016 \\
\hline & $(0.14)$ & $(0.21)$ & $(0.09)$ & $(0.02)$ & $(0.04)$ & $(0.02)$ \\
\hline \multirow[t]{2}{*}{ Urban } & $0.473^{* * *}$ & $0.529^{* * *}$ & $0.502^{* * *}$ & $0.069^{* * *}$ & $0.085^{* * *}$ & $0.076^{* * *}$ \\
\hline & $(0.05)$ & $(0.08)$ & $(0.04)$ & $(0.01)$ & $(0.01)$ & $(0.01)$ \\
\hline \multirow[t]{2}{*}{ Mom yrs of sch. } & $0.092^{* * *}$ & $0.088^{* * *}$ & $0.114^{* * *}$ & $0.009 * * *$ & $0.008^{* * *}$ & $0.010^{* * *}$ \\
\hline & $(0.01)$ & $(0.01)$ & $(0.00)$ & $(0.00)$ & $(0.00)$ & $(0.00)$ \\
\hline \multirow[t]{2}{*}{ Dad Yrs of sch. } & $0.050^{* * *}$ & $0.061^{* * *}$ & $0.062^{* * *}$ & $0.007^{* * *}$ & $0.010^{* * *}$ & $0.008^{* * *}$ \\
\hline & $(0.01)$ & $(0.01)$ & $(0.00)$ & $(0.00)$ & & $(0.00)$ \\
\hline $\mathrm{N}$ & 24124 & 8116 & 48960 & 24155 & 8110 & 49048 \\
\hline $\mathrm{F}$ & 168.88 & 71.87 & - & & & \\
\hline $\mathrm{P}(\mathrm{F})$ & 0.000 & 0.000 & - & & & \\
\hline$R^{2}$ & 0.492 & 0.481 & 0.476 & & & \\
\hline$\chi^{2}$ & & & & 1646.86 & 690.64 & 2658.44 \\
\hline$P>\left(\chi^{2}\right)$ & & & & 0.000 & 0.000 & 0.000 \\
\hline Pseudo $R^{2}$ & & & & 0.203 & 0.207 & 0.190 \\
\hline
\end{tabular}

Note: Also controlled for age, race, family size, disability, employment status of father, automobile ownership, wall type, computer ownership, class of father's work, class of mother's work, mother's number of children, and department.

Note: ${ }^{*} p<0.05,{ }^{* *} p<0.01,{ }^{* * *} p<0.001$

reasons.

First, although it is impossible to control for all possible factors that affect educational enrollment and attainment, we are able to control for most of the factors that have been shown in the past empirical and theoretical literature to be important for enrollment and accumulation. Our relatively high R-squared is one indicator that our educational accumulation model is relevant and explains a significant portion of the variation in schooling and enrollment. Second, although there are other possible variables we do not control for, such as ability, we do not worry too much about such variables as their distribution should be similar among IDPs and the comparison groups. In this scenario, the estimated gap would not be biased by their omission.

It is important at this point to mention that our inclusion of some important variables that 
Table 12: Who are we capturing?

\begin{tabular}{lccc}
\hline \hline Age & Total & With Both Parents & Percentage \\
\hline $6-11$ & 261,469 & 180,912 & $69.19 \%$ \\
$12-17$ & 250,349 & 158,347 & $63.25 \%$ \\
\hline \hline
\end{tabular}

predict enrollment and accumulation creates secondary effects. We control for parents education, and not every child in our sample has this information. Our inclusion of parent education variables in all the above analysis implies that our above analysis was not conducted on our whole sample of children ages $6-17$. Table 12 provides a breakdown and highlights what percentage in each age range falls into the sample that we used in our above analysis. Among children 6-11 years, we use only about $70 \%$ of the sample. For children $12-17$ years, we use only about $63 \%$ of the sample. This raises the question of whether an analysis on the whole sample would lead to a different outcome.

To investigate this possibility, we first estimate the bias created in our estimate of the gap if we do not include all the parent related variables. To find this bias we re-estimate both our accumulation and enrollment models with and without the parental related variables, including both migrants and non-migrants and restricting our sample to those who have parent information. The results from this analysis are summarized in Tables 13 and 14. Notice that the results in columns (1) and (4) are a repetition of earlier analysis and the results in column (2) and (5) are the estimated coefficients if parental controls are not included for the same sample. The upward bias in the estimates is significant if we do not include parental controls. Specifically for children 6-11, without parental controls we overestimate the impact of direct contact with violence on school accumulation by 0.071 and overestimate the probability of enrollment gap for those affected by violence by 0.013 .

For children 12-17, if we do not include parental controls, we overestimate the direct impact of contact with violence on school accumulation by 0.177 years and overestimate the probability of enrollment gap for those affected by violence by 0.022. Given our knowledge on the potential bias caused by not including parental controls, we re-estimate equation (2) without parental controls on the whole sample. This means that the observations that were not included previously because of missing information about parental controls are now included in the analysis. These estimates on the whole sample using both the education accumulation enrollment models are summarized in Table 15 columns (1), (3), (5) and (7). Notice that for the children 6-11 years old, these estimates are very similar to the estimates we got for the sample that have parental control when such controls were dropped and the gap estimated. For the secondary aged children the difference is slightly larger.

In columns (2), (4), (6) and (8), we present the corrected estimate of the education accumulation 
Table 13: Education Gap: Parental Controls v. No Parental Controls (Ages 6-11)

\begin{tabular}{lcccccc}
\hline \hline Variable: & \multicolumn{2}{c}{ Education Accumulation Model } & \multicolumn{3}{c}{ Probability Model } \\
\hline & $(1)$ & $(2)$ & $(3)$ & $(4)$ & $(5)$ & $(6)$ \\
\hline & Parental & No Parental & Difference & Parental & No Parental & Difference \\
\hline & control & controls & $(2)-(1)$ & controls & controls & $(5)-(4)$ \\
\hline IDP & $-0.197^{* * *}$ & $-0.268^{* * *}$ & 0.071 & $-0.016^{*}$ & $-0.029^{* * *}$ & 0.013 \\
$\mathrm{~N}$ & 171083 & 171083 & & 171393 & 171393 & \\
$\mathrm{~F}$ & 1635.96 & 1677.78 & & & & \\
$P>(F)$ & 0.000 & 0.000 & & & & \\
$R^{2}$ & 0.663 & 0.648 & & & & \\
$\chi^{2}$ & & & & 5709.09 & 5571.68 & \\
$P>\chi^{2}$ & & & & 0.000 & 0.000 & \\
PseudoR & & & & 0.152 & 0.123 & \\
\hline \hline
\end{tabular}

Note: Also controlled for sex, conflict, capacity, urban, mothers years of schooling and fathers years of schooling, age, race, family size, disability, employment status of father, automobile ownership, wall type, computer ownership, class of father's work, class of mother's work, mother's number of children, state and reasons for migration.

Note: ${ }^{*} p<0.05,{ }^{* *} p<0.01,{ }^{* * *} p<0.001$

Base group: non-migrants.

and enrollment gaps using the estimated effect of not including parental controls highlighted in Tables 13 and 14. This bias correct estimates will be valid as long the distribution when we use the sample with parent control is no different from the distribution when we use the whole sample. One way to check for the non selectivity of the sample without parental controls is to test for differences in means on a set of demographic and economic variables for the sample with parental controls and the whole sample, restricting these samples to families with children aged 6-11 and 12-17. We find that the means are almost identical for all variables apart from family size. For family size, the 6-11 years sample with parental controls have a mean of 5.7 while the mean of the whole sample is 5.54 . In the 12-17 years range, the sample with parental controls has a mean of 5.86 , while the sample without parental controls has a mean of 5.31. The results of our means test suggest that the sample without parental controls is very similar to the sample with parental controls, particularly for the 6-11 age range.

\subsection{Robustness checks: Fixed Effects}

As a final check on the validity of our earlier results we employ a fixed effect estimation technique. The choice of this technique eliminates potential bias caused by omitted variables at the municipal level. For example, pressure to leave school was one of the potential omitted variables we try to deal with by looking solely at municipalities with high conflict. However, it is possible to argue that 
Table 14: Education Gap: Parental Controls v. No Parental Controls (Ages 12-17)

\begin{tabular}{lcccccc}
\hline \hline Variable: & \multicolumn{2}{c}{ Education Accumulation Model } & \multicolumn{3}{c}{ Probability Model } \\
\hline & $(1)$ & $(2)$ & $(3)$ & $(4)$ & $(5)$ & $(6)$ \\
\hline & Parental & No Parental & Difference & Parental & No Parental & Difference \\
\hline & control & controls & $(2)-(1)$ & controls & controls & $(5)-(4)$ \\
\hline IDP & $-0.515^{* * *}$ & $-0.692^{* * *}$ & 0.177 & $-0.063^{* * *}$ & $-0.085^{* * *}$ & 0.022 \\
& $(0.09)$ & $(0.10)$ & & $(0.02)$ & $(0.02)$ & \\
$\mathrm{N}$ & 148447 & 148447 & & 148650 & 148650 & \\
$\mathrm{~F}$ & 777.69 & 734.11 & & & & \\
$P(F)>0$ & 0 & 0 & & & & \\
$R^{2}$ & 0.4741 & 0.4366 & & 7444.77 & 7696.18 & \\
$\chi^{2}$ & & & 0 & 0 & \\
$P>\chi^{2}$ & & & & 0.1964 & 0.1752 & \\
Pseudo $R^{2}$ & & & & &
\end{tabular}

Note: Also controlled for sex, conflict, capacity, urban, mothers years of schooling and fathers years of schooling, age, race, family size, disability, employment status of father, automobile ownership, wall type, computer ownership, class of father's work, class of mother's work, mother's number of children, state and reasons for migration.

Note: ${ }^{*} p<0.05,{ }^{* *} p<0.01,{ }^{* * *} p<0.001$

Base group: non-migrants. The sample above is restricted to those who have parental controls only.

Table 15: Estimated Education Gap between Non-Migrants and those directly in contact with conflict for Sample With or Without Parental Controls

\begin{tabular}{|c|c|c|c|c|c|c|c|c|}
\hline \multirow[t]{4}{*}{ Variable: } & \multicolumn{4}{|c|}{ Age 6-11 } & \multicolumn{4}{|c|}{ Age $12-17$} \\
\hline & Yrs of sch. & Yrs of sch & Enroll & Enroll & Yrs of sch. & Yrs of sch & Enroll & Enroll \\
\hline & & Corrected & & Corrected & & Corrected & Enroll & Corrected \\
\hline & (1) & (2) & (3) & (4) & (5) & (6) & $(7)$ & (8) \\
\hline Violence & $\begin{array}{c}-0.264^{* * *} \\
(0.04)\end{array}$ & 0.193 & $\begin{array}{c}-0.029^{* * *} \\
(0.01)\end{array}$ & 0.016 & $\begin{array}{c}-0.669^{* * *} \\
(0.09)\end{array}$ & -0.492 & $\begin{array}{c}-0.073^{* * *} \\
(0.02)\end{array}$ & -0.051 \\
\hline $\mathrm{N}$ & 184128 & & 184878 & & 160686 & & 161497 & \\
\hline $\mathrm{F}$ & 1759.36 & & 787.88 & & & & & \\
\hline$P(F)>0$ & 0.00 & & & & 0.000 & & & \\
\hline$R^{2}$ & 0.64 & & & & 0.424 & 0 . & & \\
\hline$\chi^{2}$ & & & 8119.97 & & & & 8735.37 & \\
\hline$P>\chi^{2}$ & & 0.000 & & 0.000 & & & & \\
\hline Pseudo $R^{2}$ & & & 0.135 & & & 0.172 & & \\
\hline
\end{tabular}

Note: Also controlled for sex, conflict, capacity, urban, age, race, family size, disability, automobile ownership, wall type, computer ownership, state and reasons for migration.

$* p<0.05,{ }^{* *} p<0.01,{ }^{* * *} p<0.001$ 
not all high conflict regions face similar pressure to quit and so the problem of this omitted variable still persists. Another possible argument is that although we control for the impact of capacity and conflict on the education outcomes we are interested in using the HSRI indices, the use of these indexes which are a composite of several other variables might not still be an effective control for the differences in conflict, social and economic capacity across municipalities. To provide evidence that our results are not driven in part by measurement error or omitted variables that vary at the municipality level, we introduced a fixed effect for municipalities. By including a municipality fixed effect, we are able to control for all possible omitted variables that could affect our outcomes of interest but vary at the municipality level. Still, the use of municipality fixed effects does not deal with any omitted variable that varies within the municipality. We have controlled for such variables in our analysis. However, we cannot rule out the possibility that there might be other potential variables that affect education outcomes that we do not control for. One possible example is ability. We do not worry so much about not controlling for variables like this because though they can affect education accumulation, they are not distributed differently across the groups we compare and hence cannot influence the gap we are interested in estimating its size.

The results in Table 16 confirm our earlier results. In columns (1) and (2), we summarize the results comparing IDPs and other migrant groups to non-migrants. In columns (3) and (4), we compare IDPs solely to migrants. These results are our preferred estimates and suggest that children ages 6-11 who are directly exposed to conflict have approximately $1 / 5$ of a year less schooling than non-migrants and about half a year less of schooling than children of non-migrants for children ages 12-17. If we look solely at migrants, we do not find any evidence of a gap among younger children but we find evidence of a gap of about 0.3 year among the older children. We are unable to use the fixed effect technique for our enrollment model that we previously estimate using a probit model. This is because there does not exist an adequate statistic for conditioning out of the likelihood and estimates based on assuming an uncondition fixed effect are biased (See Stata manual on fixed effect and probit models for more details). A not so perfect alternative is to estimate a linear probability model. Although the linear probability specification of the binary choice model provides ease of interpretation, unless restrictions are placed on estimates, coefficients can imply probabilities outside the unit interval. The results of the estimation of the enrollment model using fixed effects and assuming a linear probability model are in Table 17. These estimates provide some evidence of an enrollment gap but the evidence is mixed. We are more cautious about interpreting these estimates given the potential issue with the linear model. 
Table 16: Does being directly affected by conflict create an education gap (Fixed Effects )?

\begin{tabular}{lcccc}
\hline \hline Variable: & IDP versus & migrants and non-migrants) & \multicolumn{2}{c}{ IDP versus other migrants } \\
\hline & 6 -11 year old & $12-17$ year old & 6 -11 year old & $12-17$ year old \\
& $(1)$ & $(2)$ & $(3)$ & $(4)$ \\
\hline Violence & $-0.199^{* * *}$ & $-0.487^{* * *}$ & -0.035 & $-0.277^{* * *}$ \\
& $(0.02)$ & $(0.05)$ & $(0.02)$ & $(0.05)$ \\
Sex & $-0.163^{* * *}$ & $-0.588^{* * *}$ & $-0.133^{* * *}$ & $-0.509^{* * *}$ \\
& $(0.01)$ & $(0.01)$ & $(0.01)$ & $(0.02)$ \\
urban & $0.048^{* * *}$ & $0.442^{* * *}$ & $0.036^{* *}$ & $0.385^{* * *}$ \\
& $(0.01)$ & $(0.01)$ & $(0.01)$ & $(0.03)$ \\
Mother Yrs sch. & $0.054^{* * *}$ & $0.134^{* * *}$ & $0.048^{* * *}$ & $0.121^{* * *}$ \\
& $(0.00)$ & $(0.00)$ & $(0.00)$ & $(0.00)$ \\
Father Yrs sch. & $0.026^{* * *}$ & $0.073^{* * *}$ & $0.020^{* * *}$ & $0.064^{* * *}$ \\
& $(0.00)$ & $(0.00)$ & $(0.00)$ & $(0.00)$ \\
\hline $\mathrm{N}$ & 171083 & 148447 & 34457 & 24124 \\
$\mathrm{~F}$ & 777.69 & 752.89 & & \\
$P(F)>0$ & 0.000 & 0.000 & 0.000 & 0.000 \\
$R^{2}$ & 0.620 & 0.430 & 0.650 & 0.450 \\
$\chi^{2}$ & & & \\
$P>\chi^{2}$ & & & & \\
Pseudo $R^{2}$ & & & & \\
\hline \hline
\end{tabular}

Note: Also controlled for age, race, family size, disability, employment status of father, automobile ownership, wall type, computer ownership, class of father's work, class of mother's work, mother's number of children. In column (1) and (2) we control for migration status so dummies for other types of migrants are estimated but not presented. The base group is non-migrants. In column (3) and (4) we have a binary indicator $I D P=1$ and Other migrants $=0$

Note: ${ }^{*} p<0.05,{ }^{* *} p<0.01,{ }^{* * *} p<0.001$

\section{Summary and Conclusion}

In this paper we try to answer four questions related to the impact of conflict. We are motivated by the fact that most past research has looked at exposure to conflict and its potential effects on education accumulation and enrollment. However, we are of the opinion that looking directly at those who are affected by conflict should provide us with a better sense of the impact of conflict. Our first question is focused on whether there is an education enrollment and accumulation gap for children of those who live in municipalities with high conflict in comparison to others. Next, we address the question of whether there is an education accumulation and enrollment gap for children of those directly affected by conflict? Third, we investigate if living in a municipality with high 
Table 17: Does being directly affected by conflict create an enrollment gap-Estimates using a Linear probability model with Fixed Effects?

\begin{tabular}{lcccc}
\hline \hline Variable: & Migrants and Non Migrants & \multicolumn{2}{c}{ Migrants } \\
\hline & $6-11$ year old & $12-17$ year old & $6-11$ year old & $12-17$ year old \\
& $(1)$ & $(2)$ & $(3)$ & $(4)$ \\
\hline Violence & -0.009 & $-0.026^{* * *}$ & $-0.010^{*}$ & -0.014 \\
& $(0.01)$ & $(0.01)$ & $(0.01)$ & $(0.01)$ \\
sex & $-0.013^{* * *}$ & $-0.058^{* * *}$ & $-0.012^{* * *}$ & $-0.050^{* * *}$ \\
& $(0.00)$ & $(0.00)$ & $(0.00)$ & $(0.00)$ \\
urban & $0.037^{* * *}$ & $0.087^{* * *}$ & $0.040^{* * *}$ & $0.104^{* * *}$ \\
& $(0.00)$ & $(0.00)$ & $(0.00)$ & $(0.01)$ \\
Mother Yrs sch. & $0.007^{* * *}$ & $0.011^{* * *}$ & $0.007^{* * *}$ & $0.011^{* * *}$ \\
& $(0.00)$ & $(0.00)$ & $(0.00)$ & $(0.00)$ \\
Father Yrs sch. & $0.003^{* * *}$ & $0.007^{* * *}$ & $0.003^{* * *}$ & $0.007^{* * *}$ \\
& $(0.00)$ & $(0.00)$ & $(0.00)$ & $(0.00)$ \\
\hline $\mathrm{N}$ & 171393 & 148650 & 34510 & 24158 \\
$\mathrm{~F}$ & 284.82 & 530.42 & 63.28 & 97.43 \\
$P(F)>0$ & 0.000 & 0.000 & 0.000 & 0.000 \\
$R^{2}$ & 0.099 & 0.172 & 0.916 & 0.169 \\
Pseudo $R^{2}$ & & & & \\
\hline \hline
\end{tabular}

Note: Also controlled for age, race, family size, disability, employment status of father, automobile ownership, wall type, computer ownership, class of father's work, class of mother's work, mother's number of children.

In column (1) and (2) we control for migration status so dummies for other types of migrants are estimated but not presented. The base group is non-migrants. In column (3) and (4) we have a binary indicator $I D P=1$ and Other migrants $=0$

Note: ${ }^{*} p<0.05,{ }^{* *} p<0.01,{ }^{* * *} p<0.001$

conflict creates similar education accumulation and enrollment gaps as being directly affected by conflict. Finally, we consider how IDPs compare to other migrants in education accumulation and enrollment.

Using OLS and probit analysis to estimate our accumulation and enrollment models respectively, first we find that though there appears to be a gap in enrollment and accumulation for children of those who live in municipalities with high conflict in comparison to others, this gap does not appear to be robust. Next, we find evidence of an education accumulation and enrollment gaps for children of those who have been directly affected by conflict in comparison to non-migrants. We also find that living in a high conflict area does not create an identical effect as being directly affected by conflict. Education enrollment and accumulation gaps exist between IDPs and others who live in 
such regions. Moreover, in comparison to the education gap between IDPs and non-migrants in general, the gap between IDPS and non-migrants living in a high conflict areas is larger. Similarly, the gap between IDPs and other migrants living in a high conflict area is larger than the gap between IDPs and all migrants. Finally, our results suggest that in general, the children of IDPs fare worse than other migrants with respect to education accumulation and enrollment. This result is robust to dropping education migrants from the dataset. However if we restrict our sample to migrants in high conflict regions, we find mixed evidence for an accumulation and enrollment gap for elementary school students but strong evidence of a gap at the secondary school level. We provide evidence that this gap is not linked to some form of selectivity of IDPs who end up in high conflict area. Children of IDPs in general exhibit this gap, especially at the secondary level. We test the robustness of our results using fixed effects and although the estimates differ slightly, the basic inference of a significant impact of being directly affected by conflict persists, particularly at the secondary level.

Several suggestions can be drawn from these results. First, having a parent who was directly affected by conflict negatively affects a child's education accumulation and enrollment. This gap grows as the child grows older. In contrast, mere exposure to conflict as captured by living in an area with high conflict does not seem to have as much impact on a child's education accumulation and enrollment. Given the large literature that estimates the impact of conflict using exposure, our results suggest the need to isolate those directly affected by conflict and collect more data on their specific experiences. This kind of data would be useful in helping to create a framework for better understanding the channels through which being directly affected by conflict affects education and other labor market outcomes. Finally, although the above suggestions are relevant for studies looking at conflict of the type similar to that of Colombia, it is possible that if we looked at a different kind of conflict like a high-intensity civil war, exposure on its own might be as important as being directly affected. 


\section{References}

[1] 2009 Global Trends: Refugees, Asylum-seekers, Returnees, Internally Displaced and Stateless Persons. (2010). United Nations High Commissioner for Refugees. Retrieved August 18th 2011 http://www . unher .org/4c11f0be9.pdf

[2] Akresh, Richard and Damien de Walque (2008). Armed Conflict and Schooling: Evidence from the 1994 Rwandan Genocide. The World Bank, Policy Research Working Paper Series: 4606.

[3] Angrist, Joshua, Eric Bettinger, and Michael Kremer (2006). Long-Term Consequences of Secondary School Vouchers: Evidence from Administrative Records in Colombia. The American Economic Review, 96(3), 847-862.

[4] Angrist, Joshua, Eric Bettinger, Erik Bloom, Elizabeth King, and Michael Kremer (2002). Vouchers for Private Schooling in Colombia: Evidence from a Randomized Natural Experiment. The American Economic Review, 92(5): 1535-1558.

[5] Barrera-Osorio, Felipe, and Ana Maria Ibáñez (2004). Does Violence Reduce Investment in Education?: A Theortetical and Empirical Approach. Documentos CEDE 002382, Universidad de los Andes-CEDE.

[6] Chamarbagwala, Rubiana, and Hilc'as E. Morán (2011). The human capital consequences of civil war: Evidence from Guatemala. Journal of Development Economics, 94(1): 41-61.

[7] Dueñas, Lusia Fernanda and Fabio Sanchez (2007). Does Armed Conflict Affect the Poorest?: The Case of School Dropout in Eastern Colombia. Working Paper, Universidad de los Andes.

[8] Duryea, Suzanne, David Lam, and Deborah Levison (2001). Effects of Economic Shocks on Children's Employment and Schooling in Brazil. Journal of Development Economics, 84(1):pp $188-214$

[9] Evans, David K., and Edward Miguel (2007). Orphans and Schooling in Africa: A Longitudinal Analysis. Demography, 44(1): 35-57.

[10] Glewwe, Paul, and Hanan Jacoby (1994). Student Achievement and Schooling Choice in LowIncome Countries: Evidence from Ghana. The Journal of Human Resources, 29(3): 843-864.

[11] Gaston, Noel, and Jaime Tenjo (1992). Education Attainment and Earnings Determination in Colombia. Economic Development and Cultural Change, 41:pp 125-139. 
[12] Ibánez, Ana Maria, and Andres Moya (2006). Como el Desplazamiento Forzado Deteriora el Bienestar de los Hogares Desplazados?: Analisis y Determinantes del Bienestar en los Municipios de Recepcion. Documento CEDE No. 2006-26. Universidad de los Andes.

[13] Ibáñez, Ana Maria, and Andres Moya (2009). Vulnerability of Victims of Civil Conflicts: Empirical Evidence for the Displaced Population in Colombia. World Development, 38(4): 647-663.

[14] Jacoby, Hanan G., and Emmanuel Skoufias (1997). Risk, Financial Markets, and Human Capital in a Developing Country. Review of Economic Studies, 64(3): 311-335.

[15] Kirchhoff, Stefanie, and Ana Maria Ibáñez (2002). Displacement due to Violence in Colombia: Determinates and Consequences at the Household Level. Discussion Papers 18754, University of Bonn, Center for Development Research (ZEF).

[16] Lozano-Gracia, Nancy, and Gianfranco Piras, Ana Maria Ibáñez, and Geoffrey J.D. Hewings (2010). The Journey to Safety: Conflict-Driven Migration Flows in Colombia. International Regional Science Review, 33(2): 157-180.

[17] McKenzie, David, and Hillel Rapoport (2010). Can Migration Reduce Educational Attainment? Evidence from Mexico. Journal of Population Economics, 24(4): 1331-1358.

[18] Poveda, Alexander Cotte, and Jin Anthony Cotrino Sossa (2006). Crecimiento Econ-mico y Distribuci - n del Ingreso en Colombia: Evidencia Sobre el Capital Humano y el Nivel de Educaci-n. Serie de Documentos en Economia y Violencia 002221, Centro de Investigaciones en Violencia, Instituciones y Desarrollo Economico (VIDE).

[19] Psacharopoulos, George \& Velez, Eduardo, (1992). Schooling, Ability, and Earnings in Colombia, 1988, Economic Development and Cultural Change, University of Chicago Press, vol. 40(3), pages 629-43, April.

[20] Psacharopoulos, George \& Eduardo Velez (1993). Educational Quality and Labor Market Outcomes: Evidence from Bogota, Colombia. Sociology of Education, 66(2): 130-145.

[21] Psacharopoulos, George. (1994). Returns to Investment in Education: A Global Update. World Development 22(9): 1325-43.

[22] Rodriguez, Catherine and Fabio Sanchez (2009). Armed Conflict Exposure, Human Capital Investments and Child Labor: Evidence from Colombia. HiCN Working Papers, 68. 
[23] Staiger, D. and Stock, J., (1997). Instrumental Variable Regression with Weak Instruments. Econometrica 65:557-586.

[24] Shemyakina, Olga (2011). The Effect of Armed Conflict on Accumulation of Schooling: Results from Tajikistan. Journal of Development Economics, 95(2): 186-200.

[25] Thomas, Duncan, Kathleen Beegle, Elizabeth Frankenberg, Bondan Sikoki, John Strauss and Graciela Teruel (2004). Education in a Crisis. Journal of Development Economics, 74 (1):53-85. 2004. 


\section{Appendix}

Table 18: Are IDPs different? Ages 6-11

\begin{tabular}{lcccccc}
\hline \hline Variable: & \multicolumn{3}{c}{ Education Accumulation Model } & \multicolumn{3}{c}{ School Enrollment Model } \\
& All & Migrants & All obs & All & Migrants & All \\
& Migrants & Conf $(>0.3)$ & with Conf $(>0.3)$ & Migrants & Conf $(>0.3)$ & with Conf $(>0.3)$ \\
& $(1)$ & $(2)$ & $(3)$ & $(4)$ & $(5)$ & $(6)$ \\
\hline IDP & $-0.095^{* *}$ & -0.084 & $-0.105^{* *}$ & $-0.014^{*}$ & $-0.024^{* *}$ & -0.008 \\
& $(0.04)$ & $(0.06)$ & $(0.04)$ & $(0.01)$ & $(0.01)$ & $(0.01)$ \\
Sex & $-0.105^{* * *}$ & $-0.145^{* * *}$ & $-0.166^{* * *}$ & $-0.009^{* * *}$ & $-0.008^{*}$ & $-0.010^{* * *}$ \\
& $(0.01)$ & $(0.03)$ & $(0.02)$ & $(0.00)$ & $(0.00)$ & $(0.00)$ \\
Conflict & -0.048 & 0.084 & -0.023 & -0.006 & -0.001 & $-0.032^{* * *}$ \\
& $(0.04)$ & $(0.06)$ & $(0.04)$ & $(0.01)$ & $(0.01)$ & $(0.01)$ \\
Capacity & $0.144^{* * *}$ & $0.252^{* * *}$ & $0.286^{* * *}$ & 0.002 & 0.002 & $0.022^{* *}$ \\
& $(0.05)$ & $(0.08)$ & $(0.05)$ & $(0.01)$ & $(0.01)$ & $(0.01)$ \\
Urban & -0.020 & -0.016 & 0.009 & $0.009^{* * *}$ & $0.014^{* * *}$ & $0.023^{* * *}$ \\
& $(0.02)$ & $(0.03)$ & $(0.02)$ & $(0.00)$ & $(0.00)$ & $(0.00)$ \\
Mom yrs of sch. & $0.041^{* * *}$ & $0.039^{* * *}$ & $0.049^{* * *}$ & $0.004^{* * *}$ & $0.005^{* * *}$ & $0.007^{* * *}$ \\
& $(0.00)$ & $(0.00)$ & $(0.00)$ & $(0.00)$ & $(0.00)$ & $(0.00)$ \\
Dad yrs of sch. & $0.018^{* * *}$ & $0.027^{* * *}$ & $0.021^{* * *}$ & $0.003^{* * *}$ & $0.003^{* * *}$ & $0.003^{* * *}$ \\
& $(0.00)$ & $(0.00)$ & $(0.00)$ & $(0.00)$ & $(0.00)$ & $(0.00)$ \\
\hline $\mathrm{N}$ & 59811 & 18975 & 57815 & 59809 & 19000 & 57893 \\
$\mathrm{~F}$ & 712.62 & 252.27 & & & & \\
$P(F)>0$ & 0.000 & 0.000 & & & & \\
$R^{2}$ & 0.692 & 0.6743 & 0.6469 & & & \\
$\chi^{2}$ & & & & 1628.8 & 737.16 & 2541.03 \\
$P>\chi^{2}$ & & & & 0.000 & 0.000 & 0.000 \\
Pseudo $R^{2}$ & & & & 0.143 & 0.136 & 0.173 \\
\hline \hline
\end{tabular}

Note: Also controlled for age, race, family size, disability, employment status of father, automobile ownership, wall type, computer ownership, class of father's work, class of mother's work, mother's number of children, and department.

Note: ${ }^{*} p<0.05,{ }^{* *} p<0.01,{ }^{* * *} p<0.001$

Note: Selection implies restricting the sample to subgroup which contains all IDPs and migrants leaving in region with high conflict. 
Table 19: Are IDPs different? Ages 12-17

\begin{tabular}{|c|c|c|c|c|c|c|}
\hline \multirow[t]{3}{*}{ Variable: } & \multicolumn{3}{|c|}{ Education Accumulation Model } & \multicolumn{3}{|c|}{ School Enrollment Model } \\
\hline & All & Migrants & All obs & All & Migrants & All \\
\hline & $\begin{array}{l}\text { Migrants } \\
\text { (1) }\end{array}$ & $\begin{array}{c}\text { Conf }(>0.3) \\
(2)\end{array}$ & $\underset{(3)}{\text { with Conf }}(>0.3)$ & $\begin{array}{l}\text { Migrants } \\
\text { (4) }\end{array}$ & $\begin{array}{c}\text { Conf }(>0.3) \\
(5)\end{array}$ & $\begin{array}{c}\text { with Conf }(>0.3) \\
(6)\end{array}$ \\
\hline IDP & $\begin{array}{c}-0.412^{* * *} \\
(0.09)\end{array}$ & $\begin{array}{c}-0.440^{* * *} \\
(0.13)\end{array}$ & $\begin{array}{c}-0.443^{* * *} \\
(0.09)\end{array}$ & $\begin{array}{c}-0.051^{* * *} \\
(0.02)\end{array}$ & $\begin{array}{c}-0.101^{* * *} \\
(0.03)\end{array}$ & $\begin{array}{c}-0.057^{* * *} \\
(0.02)\end{array}$ \\
\hline Sex & $\begin{array}{c}-0.462^{* * *} \\
(0.03)\end{array}$ & $\begin{array}{c}-0.478^{* * *} \\
(0.05)\end{array}$ & $\begin{array}{c}-0.506^{* * *} \\
(0.03)\end{array}$ & $\begin{array}{c}-0.037^{* * * *} \\
(0.01)\end{array}$ & $\begin{array}{c}-0.039^{* * *} \\
(0.01)\end{array}$ & $\begin{array}{c}-0.050^{* * *} \\
(0.01)\end{array}$ \\
\hline Conflict & $\begin{array}{r}-0.066 \\
(0.08)\end{array}$ & $\begin{array}{l}0.056 \\
(0.12)\end{array}$ & $\begin{array}{c}-0.131^{*} \\
(0.07)\end{array}$ & $\begin{array}{l}-0.016 \\
(0.01)\end{array}$ & $\begin{array}{l}0.004 \\
(0.02)\end{array}$ & $\begin{array}{l}-0.019 \\
(0.01)\end{array}$ \\
\hline Capacity & $\begin{array}{l}-0.159 \\
(0.10)\end{array}$ & $\begin{array}{l}-0.002 \\
(0.15)\end{array}$ & $\begin{array}{r}-0.054 \\
(0.09)\end{array}$ & $\begin{array}{r}-0.023 \\
(0.02)\end{array}$ & $\begin{array}{r}-0.012 \\
(0.03)\end{array}$ & $\begin{array}{r}-0.016 \\
(0.02)\end{array}$ \\
\hline Urban & $\begin{array}{c}0.365^{* * *} \\
(0.03)\end{array}$ & $\begin{array}{c}0.429^{* * *} \\
(0.06)\end{array}$ & $\begin{array}{c}0.502^{* * *} \\
(0.04)\end{array}$ & $\begin{array}{c}0.051^{* * *} \\
(0.00)\end{array}$ & $\begin{array}{c}0.069^{* * *} \\
(0.01)\end{array}$ & $\begin{array}{c}0.076^{* * *} \\
(0.01)\end{array}$ \\
\hline Mom yrs of sch. & $\begin{array}{c}0.099^{* * *} \\
(0.00)\end{array}$ & $\begin{array}{c}0.103^{* * *} \\
(0.01)\end{array}$ & $\begin{array}{c}0.114^{* * *} \\
(0.00)\end{array}$ & $\begin{array}{c}0.010^{* * *} \\
(0.00)\end{array}$ & $\begin{array}{c}0.009^{* * *} \\
(0.00)\end{array}$ & $\begin{array}{c}0.010^{* * *} \\
(0.00)\end{array}$ \\
\hline Dad yrs of sch. & $\begin{array}{c}0.052^{* * *} \\
(0.00)\end{array}$ & $\begin{array}{c}0.059^{* * *} \\
(0.01)\end{array}$ & $\begin{array}{c}0.062^{* * *} \\
(0.00)\end{array}$ & $\begin{array}{c}0.008^{* * *} \\
(0.00)\end{array}$ & $\begin{array}{c}0.007^{* * *} \\
(0.00)\end{array}$ & $\begin{array}{c}0.008^{* * *} \\
(0.00)\end{array}$ \\
\hline $\mathrm{N}$ & 48387 & 15512 & 48960 & 48438 & 15540 & 49048 \\
\hline $\mathrm{F}$ & 287.77 & 114.54 & & & & \\
\hline$P(F)>0$ & 0.000 & 0.000 & & & & \\
\hline$R^{2}$ & 0.482 & 0.478 & 0.476 & & & \\
\hline$P>\chi^{2}$ & & & & 0.000 & 0.000 & 0.000 \\
\hline Pseudo $R^{2}$ & & & & 0.190 & 0.192 & 0.190 \\
\hline
\end{tabular}

Note: Also controlled for age, race, family size, disability, employment status of father, automobile ownership, wall type, computer ownership, class of father's work, class of mother's work, mother's number of children, and department.

Note: ${ }^{*} p<0.05,{ }^{* *} p<0.01,{ }^{* * *} p<0.001$ 
Table 20: Humanitarian Situation Risk Index: Conflict Index

\begin{tabular}{|c|c|}
\hline Variable Name & Description \\
\hline Subversive Actions Rate & $\begin{array}{l}\text { Hostile acts by subversive groups per } 10,000 \text { inhabitants, against } \\
\text { police or civilian infrastructure. Includes attacks on police installa- } \\
\text { tion, attacks on planes, urban attacks, armed contact, ambushes and } \\
\text { sieges. }\end{array}$ \\
\hline Unilateral Attacks & Total number of incursion with no combat \\
\hline Total Confrontations & Total confrontations between Public Forces and subversive groups \\
\hline Total Deaths & Total deaths in combat \\
\hline Mine incident rate & Number of mine incidents per 10,000 inhabitants \\
\hline Homicide rate & $\begin{array}{l}\text { Homicides per } 10,000 \text { inhabitants. Common homicides include all } \\
\text { deaths by weapon with the exception of traffic-related homicides }\end{array}$ \\
\hline Council member homicide rate & Homicide rate among council members, per 10,000 inhabitants \\
\hline Union member homicide rate & Homicide rate among union members, per 10,000 inhabitants \\
\hline Teacher homicide rate & Homicide rate among teachers, per 10,000 inhabitants \\
\hline Indigenous homicide rate & Homicide rate among indigenous people, per 10,000 inhabitants \\
\hline Massacre victim rate & $\begin{array}{l}\text { Number of deaths in massacre per } 10,000 \text { inhabitants. A collective } \\
\text { homicide or massacre is committed when the total killed are four or } \\
\text { more persons. It must be committed at the same place, same time, by } \\
\text { the same authors, and against persons unable to defend themselves }\end{array}$ \\
\hline
\end{tabular}

Kidnap victim rate

Kidnap victims per 10,000 inhabitants, including both simple and extorsive kidnap victims. A kidnapping is the retention or hiding of a person in order to exchange their freedom for some resource, avoid some act, or for a publicity of political end.
FARC Groups
Number of FARC groups present
ELN Groups
Number of ELN groups present

Expulsion displacement rate

Rate of forced displacement per 10,000, where the person is forcibly expelled from the municipality

Reception displacement rate Rate of forced 4thsplacement per 10,000, where the person is forcibly expelled to the municipality 
Table 21: Humanitarian Situation Risk Index: Response Capacity Index

\begin{tabular}{ll}
\hline \hline Variable Name & Description \\
\hline $\begin{array}{l}\text { Teachers with higher educa- } \\
\text { tion }\end{array}$ & Number of teachers with higher education \\
Student:teacher ratio & Total number of students by number of teachers \\
$\begin{array}{l}\text { Middle education institutional } \\
\text { presence }\end{array}$ & Number of middle education institutions per 10,000 inhabitants \\
$\begin{array}{l}\text { SENA continuing education } \\
\text { center presence }\end{array}$ & Number of SENA institutions per 10,000 inhabitants \\
$\begin{array}{l}\text { ICBF Family Welfare Institute } \\
\text { rate }\end{array}$ & Binary value, present or not present \\
Health center presence & Number of health centers per 10,000 inhabitants \\
Vaccination coverage & Percentage of population covered by vaccinations \\
$\begin{array}{l}\text { Compensation services pres- } \\
\text { ence }\end{array}$ & Rate of compensation services present per 10,000 inhabitants \\
Judicial dispatch presence & Rate of presence of judicial dispatches per 10,000 inhabitants \\
Ponciliation center presence & Rate of presence of conciliation centers per 10,000 inhabitants \\
\hline \hline
\end{tabular}

